\title{
Trade Costs and Job Flows: Evidence from Establishment-Level Data*
}

\author{
Jose L. Groizard \\ Departament d'Economia Aplicada \\ Universitat de les Illes Balears
}

\author{
Priya Ranjan \\ Department of Economics \\ University of California, Irvine
}

\author{
Antonio Rodriguez-Lopez \\ Department of Economics \\ University of California, Irvine
}

Final version: March 2014

\begin{abstract}
Changes in the costs of trading inputs or final goods affect establishment-level job flows. Using a longitudinal database containing the universe of manufacturing establishments in California from 1992 to 2004, we find that a decline in input or final-good trade costs is associated with job destruction in the least productive establishments, job creation in the most productive establishments, and an increase in the death likelihood of the least productive establishments. The evidence is consistent with predictions of models of trade with heterogeneous firms. Additionally, the evidence shows that the effects of input trade costs on establishment-level job flows are larger than the effects of final-good trade costs.
\end{abstract}

JEL Classification: F14, F16

Keywords: heterogeneous firms, job flows, trade costs

\footnotetext{
${ }^{*}$ We thank Keith Maskus (the editor) and two anonymous referees for valuable comments and suggestions. We also thank Tomas del Barrio, Jan Brueckner, Marc Muendler, David Neumark, William Nilsson, Guillaume Rocheteau, Miaojie $\mathrm{Yu}$, and seminar and conference participants. Groizard acknowledges financial support from the Spanish Ministry of Science and Technology under Grant ECO2008-05215. All errors are our responsibility. E-mail addresses: Groizard (joseluis.groizard@uib.es); Ranjan (pranjan@uci.edu); Rodriguez-Lopez (jantonio@uci.edu).
} 


\section{Introduction}

The recent surge in input and final-good trade in the U.S. coincided with large changes in domestic employment levels. For example, in the U.S. computer and peripheral equipment industry-a sector with substantial degrees of offshoring and final-good trade - the rise in input and final-good trade coincided with the sharpest decline in employment in the industry's history: according to the Quarterly Census of Employment \& Wages (QCEW) of the Bureau of Labor Statistics (BLS), the industry lost about $44 \%$ of its workforce from 2001 to 2010. In comparison, the number of establishments in the industry declined by $28 \%$ over the same period. The large difference between the change in employment and the change in the number of establishments suggests different effects of trade costs for the intensive and extensive margins of employment; the intensive margin refers to job flows due to expansions and contractions of existing firms' employment, and the extensive margin refers to job flows due to births and deaths of firms.

To what extent are the changes in job flows related to changes in trade costs? This paper empirically investigates the impact of trade costs on establishment-level job flows, paying special attention to the role played by establishment heterogeneity. As shown in the recent models of trade with heterogeneous firms in productivity, firm heterogeneity matters for the effects of trade liberalization on aggregate productivity and welfare. In the seminal Melitz (2003) model, trade liberalization reallocates market shares towards more productive firms, forcing low-productivity firms to exit and raising the average productivity of surviving firms; Melitz and Redding (2013) show that this is a source of welfare gains that does not arise if firms are homogeneous. Importantly, the reallocation of market shares across firms goes hand in hand with the reallocation of labor: firms that exit destroy all their jobs, the ones that lose market share destroy some of their jobs, while the ones that increase their market shares may create more jobs. This makes it imperative to empirically study the insights of heterogeneous-firm models pertaining to employment changes and exit decisions of firms in response to reductions in trade costs, which is the subject of our paper.

In this paper we gauge the importance of both input trade costs and final-good trade costs. We distinguish between the two because they affect firm-level employment through different channels. In the Melitz (2003) model, firms employ only domestic labor and trade liberalization is modeled as a reduction in the variable cost of trading final goods. The model solves for two cutoff levels of productivity: one determines the tradability of each good in the domestic market, while the other-larger than the first one - determines the tradability of each good in the export market. A decline in the iceberg trade cost increases the cutoff level for selling domestically, while reducing the exporting cutoff level: although lower-productivity firms are now able to export, the competitive environment becomes tougher and some low-productivity (non-exporting) firms are forced to exit. 
Bernard, Redding, and Schott (2007) explicitly address the predictions of the Melitz's model on gross job flows. They find that after a reduction in final-good trade costs, there is gross job destruction from two sources: the death of firms with productivity levels between the old and new domestic cutoff levels, and the contraction of surviving non-exporting firms. On the other hand, there is gross job creation by expansion of existing and new exporting firms.

A reduction in input trade costs affects job flows through more channels than a reduction in final-good trade costs. We provide a simple model that allows us to identify the channels through which input trade affects job flows. The model assumes fixed costs of offshoring and therefore, only the most productive firms offshore. As offshored inputs become cheaper, there is a substitution effect as offshoring firms replace inputs produced within the firm boundary with foreign inputs, leading to a decrease in firm-level employment. However, the lower cost of offshored inputs decreases the marginal cost of offshoring firms, allowing them to set lower prices and capture larger market shares; this scale effect is a source of job creation. Lastly, as offshoring firms become more efficient, the competitive environment becomes tougher (this is the competition effect), which leads to a reduction in firm-level employment. After a decline in input trade costs, non-offshoring firms are only subject to the competition effect, which drives the least productive firms to exit and the surviving firms to contract and hence destroy labor. On the other hand, offshoring firms are subject to the three effects and may create jobs if the scale effect is sufficiently large.

In the end, a reduction in input and final-good trade costs have the same reduced-form predictions on firm-level employment:

1. Job destruction in continuing low-productivity firms;

2. Possible job creation in continuing high-productivity firms, which are more likely to engage in trade activities;

3. An increase in the death likelihood of low-productivity firms, which is a source of job destruction at the extensive margin.

We not only check if the predictions hold in the data, but are also able to identify which type of trade cost is quantitatively more important.

For this purpose, we use an extract of the National Establishment Time Series (NETS) database that contains the universe of manufacturing establishments in California from 1992 to 2004. After showing the high correlation between manufacturing employment in California and national manufacturing employment (even at disaggregated industry levels), we use employment levels from the NETS data to create our establishment-level job-flow variables. Each establishment is classified 
into a four-digit SIC manufacturing industry and, based on the establishment's size (as measured by its sales), we create a measure of relative productivity with respect to the establishment's industry peers. We then match every establishment with input and final-good trade cost measures.

Our trade cost measures include both a tariff and a freight component. We first calculate industry-level final-good trade costs from the U.S. trade database of Feenstra, Romalis, and Schott (2002), and then compute each industry's input trade costs following the approach of Amiti and Konings (2007). Importantly for our identification stategy, the correlation between changes in input trade costs and changes in final-good trade costs over our period of study is only 0.15. Therefore, we can separately identify the effects of both types of trade costs on establishment-level job flows by relying on industry-level variation in input and final-good trade costs.

Our establishment-level regressions confirm the three predictions above. We find that declines in input and final-good trade costs give rise to net job destruction at the intensive-margin of employment - they cause fewer job expansions and more job contractions - for low-productivity establishments, and the opposite for high-productivity establishments. We also find significant evidence of an increase in the probability of death for low-productivity establishments after a reduction in input and final-good trade costs.

Overall, the impact of input trade costs on job flows is quantitatively stronger than the impact of final-good trade costs. For example, the coefficients from our benchmark regression with threeyear differences imply that the impact of a decline in input trade costs on net job destruction in the least productive firm is 2.3 times larger than the impact of an equivalent decline in final-good trade costs. Similarly, the impact of a decline in input trade costs on the increase in net job creation in the most productive firm is 3 times larger than the impact of an equivalent decline in final-good trade costs. As well, while a one percentage point decline in input trade costs increases the death-likelihood for the least productive establishment by about $1 \%$, an equivalent increase in final-good trade costs increases it by $0.65 \%$. Moreover, the death likelihood for the most productive establishment declines by $1.1 \%$ after a one percentage point reduction in input trade costs, but it remains unchanged after a similar decline in final-good trade costs. In addition, and in contrast to changes in final-good trade costs, changes in input trade costs have statistically significant effects at the intensive-margin of employment even at one-year horizons.

The rest of the paper is organized as follows. Section 1.1 reviews related literature. Section 2 presents a comprehensive theoretical motivation for our empirical exercise. Section 3 shows some facts about the U.S. manufacturing industry and describes our establishment-level data and the trade data used. In section 4 we perform the establishment-level estimation for the relationship between trade costs and intensive-margin job flows. In section 5 we analyze the relationship be- 
tween trade costs, establishment-level productivity, and death likelihood. Section 6 presents our robustness analysis. Lastly, section 7 concludes.

\section{$1.1 \quad$ Related Literature}

The focus on establishment-level job flows - rather than on industry-level net employment changesfor the analysis of the effects of trade costs on the labor market is particularly relevant in a world with heterogeneous firms. It is not only true that net employment changes hide large changes in gross job flows (see Davis, Faberman, and Haltiwanger, 2006), but also the magnitude and direction of employment adjustments differ from firm to firm. Using Chilean plant-level data from 1979 to 1986, a period of trade liberalization, Levinsohn (1999) documents substantial differences in the rates of job creation and destruction across plants of different sizes: although the smallest plants are three times more likely to destroy jobs by firm death than the largest plants, the smallest plants have lower rates of both job creation by expansion and job destruction by contraction. ${ }^{1}$ Similarly, Biscourp and Kramarz (2007) use French firm-level manufacturing data from 1986 and 1992 and find that there is a stronger relationship between import growth and job destruction for large firms than for small firms.

A related area of research has studied the effects of other aspects of globalization on gross job flows. Klein, Schuh, and Triest (2003) analyze the effects of real exchange rate changes on job flows using industry-level data for the U.S. manufacturing sector from 1974 to 1993. They decompose the real exchange rate into its trend and cyclical components and find that the trend component has a similar effect on job creation and job destruction (with a nil net effect on employment), while the cyclical component has a net effect on employment only through job destruction. They also find that labor reallocation effects are larger in industries that are more open to trade. Along the same lines, Moser, Urban, and di Mauro (2010) study the impact of real exchange rate changes on job flows using establishment-level data for Germany from 1993 to 2005. Working first with a balanced panel (with no establishment births or deaths), they find that the bulk of the employment adjustment to a stronger real exchange rate occurs through less job creation rather than through increased job destruction. This result, they argue, is due to rigid labor regulations that make job destruction by contraction very costly for German firms. Once they take into account firms' deaths - through bankruptcy — job destruction becomes relevant.

After a decline in input trade costs, the theory predicts an increase in the death likelihood of low-productivity firms. The empirical approach we follow to see this pattern in the data takes the

\footnotetext{
${ }^{1}$ In advance of the heterogeneous-firm models of Bernard, Eaton, Jensen, and Kortum (2003) and Melitz (2003), Levinsohn concludes his paper by pointing out the need to include heterogeneous firms in international trade models in order to account for the observed differences in employment responses.
} 
form of a binary regression at the establishment level, where the dependent variable takes the value of 1 in the period an establishment dies (and zero otherwise). Bernard, Jensen, and Schott (2006b) work with a similar probability-of-death regression using plant-level data of U.S. manufacturing industries from 1987 to 1997 . They find that — as predicted by heterogeneous-firm models of trade in final goods - a decline in trade costs increases the death probability of firms, with a larger increase for low-productivity firms. Given that the objective of Bernard, Jensen, and Schott (2006b) is to test several predictions of the seminal heterogeneous-firm models of Bernard, Eaton, Jensen, and Kortum (2003) and Melitz (2003), they focus their empirical analysis on final-good trade costs. In our probability-of-death regressions, however, we are able to gauge the importance of both input and final-good trade costs.

In a related paper - and closer in spirit to a story of trade in intermediate inputs - Bernard, Jensen, and Schott (2006a) study the impact of imports from low-wage countries on plant survival probabilities and employment growth in the U.S. manufacturing industry from 1977 to 1997. They find a negative relationship between plant survival rates and imports from low-wage countries. As well, they find that greater import penetration from low-wage countries has a negative impact on the employment growth of surviving firms, with a smaller effect for capital-intensive plants. ${ }^{2}$

Similar to our approach, there are empirical papers that contrast the effects of input and finalgood trade costs on firm-level outcomes. Using plant-level data from Indonesia, Amiti and Konings (2007) show that a decline in input trade costs increases plant-level productivity, and Topalova and Khandelwal (2011) find the same using firm-level data from India. Moreover, the effect of input trade costs is two times larger than the effect of final-good trade costs for Indonesia, and up to ten times larger for India. Using the same Indian data, Goldberg, Khandelwal, Pavcnik, and Topalova (2010) find that a reduction in input tariffs increases the range of goods that a firm produces. In particular, they find that from 1989 to 1997, the decline in input tariffs in India accounted for 31\% of the observed expansion in within-firm product scope. Our paper differs from these studies in that we look instead at a developed economy, and we focus on establishment-level job flows (not productivity or product scope). The strong similarity is, however, that we also find that input trade costs have stronger effects than final-good trade costs for firm-level outcomes.

\section{Theoretical Motivation}

This section describes the effects of input and final-good trade costs on firm-level employment in the context of recent models of trade with heterogeneous firms. We show that both types of trade

\footnotetext{
${ }^{2}$ Supporting the findings of Bernard, Jensen, and Schott (2006a), but without looking at job flows, Ebenstein, Harrison, McMillan, and Phillips (2013) find that offshoring to low-wage countries negatively affects U.S. employment, though the effect is small.
} 
costs generate the same three predictions tested in the empirical exercise below.

\subsection{Final-Good Trade Costs and Firm-Level Employment}

For this part we rely on well-known results from the Melitz (2003) model. In that model, firms are heterogeneous in productivity and each firm produces a final differentiated good that is potentially tradable. A firms knows its productivity - which is drawn from a common distribution-after paying a sunk entry cost. Additionally, the firm must pay a fixed cost for each market it wants to access and a per-unit cost of exporting. The latter is modeled as an iceberg cost and is denoted by $1+\tau$, for $\tau>0$, so that a firm must ship $1+\tau$ units of the final good for one unit to reach the foreign market. We focus our analysis below on a decline in $\tau$.

With constant-elasticity-of-substitution (CES) preferences, these assumptions imply the existence of cutoff productivity levels for selling in the domestic $(D)$ and export $(X)$ markets: a firm with productivity $\varphi$ produces for market $r$ if and only if $\varphi \geq \hat{\varphi}_{r}$, for $r \in\{D, X\}$. The profits from selling in market $r$ are strictly increasing in productivity if $\varphi \geq \hat{\varphi}_{r}$, being equal to zero if $\varphi=\hat{\varphi}_{r}$. The model is closed by assuming free-entry conditions for home and foreign firms. It is also assumed that $\tau$ is sufficiently large so that $\hat{\varphi}_{D}<\hat{\varphi}_{X}$ in equilibrium; that is, exporting firms always sell for the domestic market.

In the model, a firm's profits and its demand for labor are directly related: more productive firms are larger, hire more labor, and make more profits. Let $L(\varphi)$ denote the demand for labor of a firm with productivity $\varphi$, where $L(\varphi)$ is positive and strictly increasing if $\varphi \geq \hat{\varphi}_{D}$ (and is zero otherwise). It follows that $L(\varphi)$ can be rewritten as

$$
L(\varphi)= \begin{cases}0 & \text { if } \varphi<\hat{\varphi}_{D} \\ L_{D}(\varphi) & \text { if } \varphi \in\left[\hat{\varphi}_{D}, \hat{\varphi}_{X}\right), \\ L_{D}(\varphi)+L_{X}(\varphi) & \text { if } \varphi \geq \hat{\varphi}_{X}\end{cases}
$$

where $L_{r}(\varphi)$ is the labor requirement of a firm with productivity $\varphi$ to produce for market $r$, for $r \in\{D, X\} .^{3}$ In fact, it can be shown that the standard Melitz model yields an expression for $L_{r}(\varphi)$ that is very simple and intuitive:

$$
L_{r}(\varphi)=(\sigma-1) f_{r}\left(\frac{\varphi}{\hat{\varphi}_{r}}\right)^{\sigma-1}
$$

if $\varphi \geq \hat{\varphi}_{r}$ (and zero otherwise), where $\sigma>1$ is the elasticity of substitution between varieties, and $f_{r}$ is the fixed cost to access market $r$. Note that for a producing firm, $L_{r}(\varphi)$ declines after an increase in $\hat{\varphi}_{r}$; i.e., $\frac{d L_{r}(\varphi)}{d \hat{\varphi}_{r}}<0$ for $\varphi \geq \hat{\varphi}_{r}$. Moreover, those firms with productivity levels between

\footnotetext{
${ }^{3}$ It is assumed that there is a perfectly elastic supply of labor, so that the equilibrium level of employment is demand-determined.
} 
the old and new $\hat{\varphi}_{r}$ stop producing for market $r$ and hence, their labor requirements to produce for that market drop to zero.

The cutoff productivity level for market $r, \hat{\varphi}_{r}$, indicates how tough it is for home firms to produce for that market. A tougher competitive environment in market $r$ increases $\hat{\varphi}_{r}$, causing lower profits and lower labor requirements. We are interested in the effects of a reduction in finalgood trade barriers; thus, the relevant point for our case is how the competitive environment in each market changes after a decline in $\tau$, and how this is reflected in firm-level employment. Denoting by $\zeta_{L_{r}(\varphi), \tau}$ and $\zeta_{\hat{\varphi}_{r}, \tau}$ the elasticities of $L_{r}(\varphi)$ and $\hat{\varphi}_{r}$ with respect to $\tau$, we obtain from (2) that

$$
\zeta_{L_{r}(\varphi), \tau}=-(\sigma-1) \zeta_{\hat{\varphi}_{r}, \tau}
$$

if $\varphi \geq \varphi_{r}$, for $r \in\{D, X\}$. From (1) and (3) it follows that the elasticity of labor demand of a firm with productivity $\varphi$ with respect to $\tau$ is

$$
\zeta_{L(\varphi), \tau}= \begin{cases}0 & \text { if } \varphi<\hat{\varphi}_{D}, \\ -(\sigma-1) \zeta_{\hat{\varphi}_{D}, \tau} & \text { if } \varphi \in\left[\hat{\varphi}_{D}, \hat{\varphi}_{X}\right), \\ -(\sigma-1)\left[\xi_{D} \zeta_{\hat{\varphi}_{D}, \tau}+\xi_{X} \zeta_{\hat{\varphi}_{X}, \tau}\right] & \text { if } \varphi \geq \hat{\varphi}_{X},\end{cases}
$$

where $\xi_{r}=\frac{f_{r} / \hat{\varphi}_{r}^{\sigma-1}}{f_{D} / \hat{\varphi}_{D}^{\sigma-1}+f_{X} / \hat{\varphi}_{X}^{\sigma-1}}$ is the share of labor devoted to production for market $r$.

Importantly, note that $\tau$ affects $L(\varphi)$ only through its impact on the cutoff levels, $\hat{\varphi}_{D}$ and $\hat{\varphi}_{X}$. We refer to the effect of $\tau$ on $\hat{\varphi}_{D}$ as the domestic-market competition effect, and to the effect of $\tau$ on $\hat{\varphi}_{X}$ as the export-market competition effect. A key result of the Melitz model is that a change in $\tau$ has opposite effects on $\hat{\varphi}_{D}$ and $\hat{\varphi}_{X}$. In particular,

$$
\zeta_{\hat{\varphi}_{D}, \tau}<0 \quad \text { and } \quad \zeta_{\hat{\varphi}_{X}, \tau}>0
$$

so that a decline in $\tau$ increases $\hat{\varphi}_{D}$ but reduces $\hat{\varphi}_{X}$. Intuitively, a reduction in $\tau$ toughens the competitive environment for selling to domestic consumers through two sources: the increase in competition from foreign exporters (who are now more competitive in the home market) and the increase in competition from new entrants (who enter the market motivated by better export opportunities, though some of them will never export, and some others will never produce for any market). On the other hand, the reduction in $\tau$ softens the competitive environment for home firms selling in the export market because the decline in trade costs allows them to sell at lower prices and capture larger market shares in the foreign market.

Given (5), it follows from (4) that $\zeta_{L(\varphi), \tau}$ equals zero if $\varphi<\hat{\varphi}_{D}$, is greater than zero if $\varphi \in\left[\hat{\varphi}_{D}, \hat{\varphi}_{X}\right)$, and its sign is ambiguous if $\varphi \geq \hat{\varphi}_{X}$. That is, after a decline in $\tau$, continuing producing firms that do not export reduce employment, while continuing exporting firms may expand or contract - note that exporting firms reduce employment devoted to production for the 


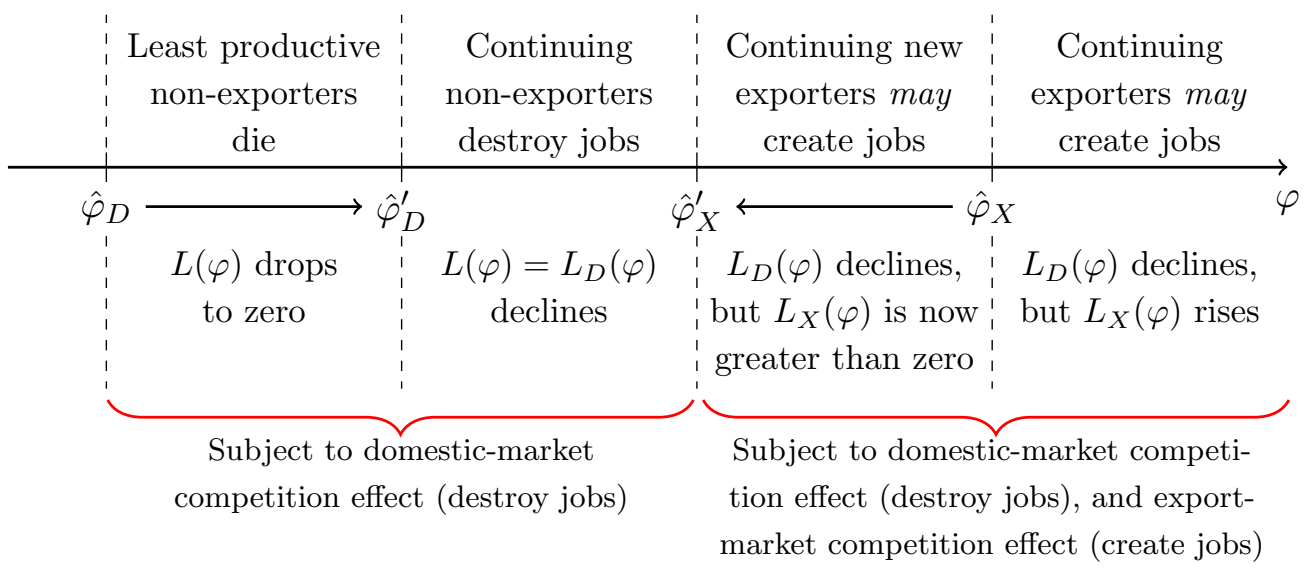

Figure 1: A reduction in final-good trade costs and firm-level employment

domestic market $\left(L_{D}(\varphi)\right.$ declines) but expand employment to produce for the export market $\left(L_{X}(\varphi)\right.$ increases). Equation (4) shows the employment responses of firms that do not change their production or export status. There are, however, some firms that stop producing and some firms that start exporting after $\tau$ falls. In the first case, $\hat{\varphi}_{D}$ increases and thus, the firms between the old and new $\hat{\varphi}_{D}$ stop producing (they reduce employment by death, with $L(\varphi)$ dropping to zero). In the second case, $\hat{\varphi}_{X}$ falls and therefore, the continuing firms between the new and old $\hat{\varphi}_{X}$ become exporters - $L_{X}(\varphi)$ jumps from zero to a positive level, which may overcome the decline in $L_{D}(\varphi)$.

Figure 1 presents a summary of the effects of a reduction in final-good trade costs on firm-level employment. There is a very clear correspondence between the theoretical implications of a decline in $\tau$ in the Melitz model of trade, and our empirical exercise below. Prediction 1 refers to job destruction in low-productivity firms, which corresponds in Figure 1 to the contraction of firms between $\hat{\varphi}_{D}^{\prime}$ and $\hat{\varphi}_{X}^{\prime}$. Prediction 2 is about the possible job creation in high-productivity firms (more likely to engage in trade), which corresponds in Figure 1 to those firms with productivities above $\hat{\varphi}_{X}^{\prime}$. Lastly, Prediction 3 refers to an increase in the death-likelihood of the least productive firms, which corresponds in Figure 1 to the death of firms between the $\hat{\varphi}_{D}$ and $\hat{\varphi}_{D}^{\prime}$.

\subsection{Input Trade Costs and Firm-Level Employment}

We now turn to the theoretical effects of a reduction in input trade costs on firm-level employment in a heterogeneous-firm setting. Given that this deviation from the original Melitz model has not received the same degree of attention, in section A in the Appendix we present a model that shows the main mechanisms through which a decline in input trade costs affects firm-level labor demand. ${ }^{4}$ In this section we present an outline of the model, discuss the effects of a decline in input trade

\footnotetext{
${ }^{4}$ The Appendix is available at http://www.socsci.uci.edu/ jantonio/Papers/tradecosts_jobflows_app.pdf.
} 
costs, and show how our three empirical predictions emerge.

As in the conventional Melitz model, consumers have CES preferences over differentiated goods, firms in the differentiated-good sector are heterogeneous in productivity, and a firm knows its productivity only after paying a sunk entry cost. The main difference is that now, differentiatedgood firms can take advantage of lower input prices in the foreign country. There are, however, fixed and variable costs of offshoring. ${ }^{5}$

The production function of a firm with productivity $\varphi$ is $z(\varphi)=\varphi Y$, with

$$
Y=\left[\alpha L^{\frac{\rho-1}{\rho}}+(1-\alpha) M^{\frac{\rho-1}{\rho}}\right]^{\frac{\rho}{\rho-1}}
$$

where $L$ is a composite of inputs produced within the firm, $M$ is a composite of inputs procured from outside the firm, and $\rho \geq 0$ is the elasticity of substitution/complementarity between the two types of inputs. We assume that one unit of labor is required to produce one unit of $L$; therefore, $L$ is directly interpreted as domestic labor. In terms of a numeraire good, the domestic wage (i.e. the cost of one unit of $L$ ) is 1 .

The composite input $M$ can be either procured domestically or it can be offshored. Let $p_{M, s}$ denote the price paid by a firm with offshoring status $s$ for a unit of composite input $M$, for $s \in$ $\{n, o\}$, where $n$ denotes "not offshoring" and $o$ denotes "offshoring". If $M$ is procured domestically, we are implicitly assuming that $p_{M, n}$ units of the numeraire good translate into one unit of input $M .^{6}$ If the production of $M$ is offshored, a firm has to pay a fixed cost of offshoring, $f_{o}$, and a variable cost, $p_{M, o}$, per unit of input $M$. Let $p_{M}^{*}$ denote the price of input $M$ in the foreign foreign country, and let $1+\lambda$ (for $\lambda>0$ ) denote the iceberg cost of offshoring. It follows that

$$
p_{M, o}=p_{M}^{*}(1+\lambda),
$$

so that a decline in $\lambda$ makes offshoring more attractive. Note that domestic firms have incentives to offshore only if $p_{M, o}<p_{M, n}$, which we assume to be the case.

Given our production function and (6), the marginal cost of a firm with productivity $\varphi$ and offshoring status $s$ is given by $\frac{c_{s}}{\varphi}$, where

$$
c_{s} \equiv\left[\alpha^{\rho}+(1-\alpha)^{\rho} p_{M, s}^{1-\rho}\right]^{\frac{1}{1-\rho}}
$$

is the price of a unit of $Y$ for a firm with status $s$, for $s \in\{n, o\}$. Given $p_{M, o}<p_{M, n}$, it follows that $\frac{c_{o}}{\varphi}<\frac{c_{n}}{\varphi}$; that is, the marginal cost of a firm with productivity $\varphi$ is always lower if the firm

\footnotetext{
${ }^{5}$ This model is related to the model of offshoring and unemployment we develop in Groizard, Ranjan, and Rodriguez-Lopez (2013). In contrast to that model, however, here we focus exclusively on input trade, and abstract from a continuum-of-inputs structure, search frictions, unemployment analysis, and final-good trade.

${ }^{6}$ In the multi-sector extension discussed below, input $M$ is a composite of the inputs purchased from other sectors of the economy.
} 
offshores. As with exporting in the benchmark Melitz model, a fixed cost of offshoring implies the existence of a cutoff productivity level, $\hat{\varphi}_{o}$, that separates offshoring and non-offshoring firms. If $\varphi<\hat{\varphi}_{o}$, the firm has offshoring status $n$; otherwise, the firm has offshoring status $o$.

There is a fixed cost of operation, $f$, for every producing firm and therefore, there is an additional cutoff productivity level, $\hat{\varphi}$, that indicates whether or not a firm produces - a firm with productivity $\hat{\varphi}$ makes zero profits. This cutoff is below $\hat{\varphi}_{o}$, so that the range of firms with productivities between $\hat{\varphi}$ and $\hat{\varphi}_{o}$ produce but do not offshore. A firm with productivity $\hat{\varphi}_{o}$ must be indifferent between offshoring or not, which allows us to to pin down the relationship between $\hat{\varphi}$ and $\hat{\varphi}_{o}$. The model is closed by assuming a free-entry condition.

As before, differentiated-good firms face perfectly elastic supplies of domestic and foreign workers, and hence, firm-level employment is demand-determined. We focus exclusively on firm-level domestic employment, which arises from the need to produce composite input $L$ within the firm boundary. Let $L(\varphi)$ denote the demand for domestic labor of a firm with productivity $\varphi$. In the Appendix we show that

$$
L(\varphi)= \begin{cases}0 & \text { if } \varphi<\hat{\varphi} \\ L_{n}(\varphi)=\alpha^{\rho}(\sigma-1) f c_{n}^{\rho-1}\left(\frac{\varphi}{\hat{\varphi}}\right)^{\sigma-1} & \text { if } \varphi \in\left[\hat{\varphi}, \hat{\varphi}_{o}\right), \\ L_{o}(\varphi)=\frac{\alpha^{\rho}(\sigma-1) f c_{n}^{\sigma-1}}{c_{o}^{\sigma-\rho}}\left(\frac{\varphi}{\hat{\varphi}}\right)^{\sigma-1} & \text { if } \varphi \geq \hat{\varphi}_{o}\end{cases}
$$

where $\sigma$ is the elasticity of substitution between differentiated goods, and $L_{s}(\varphi)$ denotes the demand for domestic labor of a firm with offshoring status $s$, for $s \in\{n, o\}$.

We are interested in the theoretical effects of a decline in input trade costs on firm-level employment. In the current setting, we look at the effects of a reduction in $\lambda$, which by (7) implies a decline in the cost of offshoring input $M$. For an existing firm with productivity $\varphi$ that does not change its producing or offshoring status $s$ after a change in $\lambda$, we obtain from (9) that the elasticity of $L(\varphi)$ with respect to $\lambda$ is

$$
\zeta_{L(\varphi), \lambda}= \begin{cases}0 & \text { if } \varphi \in\left[\hat{\varphi}, \hat{\varphi}_{o}\right) \\ -(\sigma-1) \zeta_{\hat{\varphi}, \lambda} & \text { if } \varphi \in\left[\hat{\varphi}, \hat{\varphi}_{o}\right), \\ -(\sigma-1) \zeta_{\hat{\varphi}, \lambda}+(\rho-\sigma) \zeta_{c_{o}, \lambda} & \text { if } \varphi \geq \hat{\varphi}_{o}\end{cases}
$$

where each $\zeta_{\cdot, \lambda}$ denotes an elasticity with respect to $\lambda$ (note that $c_{n}$ is independent of $\lambda$ ). For the terms on the right-hand side of (10), in the Appendix we show that

$$
\zeta_{c_{o}, \lambda}>0, \text { and } \zeta_{\hat{\varphi}, \lambda}<0
$$

That is, a reduction in the cost of offshoring implies a decrease in the marginal cost of offshoring firms, $c_{o} / \varphi$, and an increase in the cutoff productivity level above which firms survive, $\hat{\varphi}$. 
We can identify three effects on firm-level employment when $\lambda$ declines. First, there is a competition effect, which is accounted for by $-(\sigma-1) \zeta_{\hat{\varphi}, \lambda}>0$ in (10). The decline in $\lambda$ causes a tougher competitive environment as a result of entry of new firms and the decrease in prices of new and old offshoring firms. Similar to the domestic-market competition effect of a reduction in final-good trade costs, the competition effect of a reduction in input trade costs is a source of job destruction. This is the only effect present for continuing non-offshoring firms. Second, there is a substitution effect, which is accounted for by $\rho \zeta_{c_{o}, \lambda}>0$ in (10). Since offshored inputs have become cheaper relative to domestic labor, offshoring firms use more offshored inputs, $M$, and less domestic labor, $L$. The greater the elasticity of substitution between $M$ and $L, \rho$, the greater the job loss due to the substitution effect. Third, there is a scale effect, which is accounted for by $-\sigma \zeta_{c_{o}, \lambda}<0$ in (10). The decline in $\lambda$ decreases the marginal cost of offshoring firms, $\frac{c_{o}}{\varphi}$, which then allows them to set lower prices and increase their market shares. After a decline in $\lambda$, this effect is a source of job creation for offshoring firms, with its strength depending on the elasticity of demand, $\sigma$. The scale effect dominates the substitution effect if and only if $\sigma>\rho$; however, given the competition effect, the overall impact on the employment of offshoring firms is ambiguous.

Equation (10) does not capture the changes in employment of firms that change their producing or offshoring status. Given that $\hat{\varphi}$ increases after $\lambda$ declines, those firms between the old and new $\hat{\varphi}$ die and hence destroy jobs. On the other hand, $\varphi_{o}$ decreases as $\lambda$ declines $\left(\zeta_{\hat{\varphi}_{o}, \lambda}>0\right)$ and therefore, those producing firms between the new and old $\hat{\varphi}_{o}$ change their status from "not-offshoring" to "offshoring". For each of these firms, the demand for domestic labor jumps from $L_{n}(\varphi)$ to $L_{o}(\varphi)$. Note from (9) that when a firm changes from $L_{n}(\varphi)$ to $L_{o}(\varphi)$, we observe the same three effects discussed earlier for offshoring firms.

Figure 2 presents a summary of the effects of a reduction in $\lambda$ on firm-level employment. After a decline in $\lambda$, non-offshoring firms are only subject to the competition effect. The least productive of them are wiped out, and the ones that survive reduce employment. Continuing new and old offshoring firms are subject to the three effects described earlier. The substitution and competition effects cause job destruction, while the scale effect causes job creation. There is net job creation in offshoring firms only if the scale effect is sufficiently strong to dominate the other two effects. If we allow for trade in final goods, a decline in $\lambda$ also generates an export-market competition effect, which is another source of job creation: as more firms begin to offshore and their marginal costs decline, some of them become competitive in the foreign market and begin to export, which then translates into more domestic jobs (see Groizard, Ranjan, and Rodriguez-Lopez, 2013 for an extension in this direction). ${ }^{7}$

\footnotetext{
${ }^{7}$ In addition, the model we consider in Groizard, Ranjan, and Rodriguez-Lopez (2013) features a production function with a continuum of inputs in the interval $(0,1)$, in which the fraction of offshored inputs is endogenously
} 


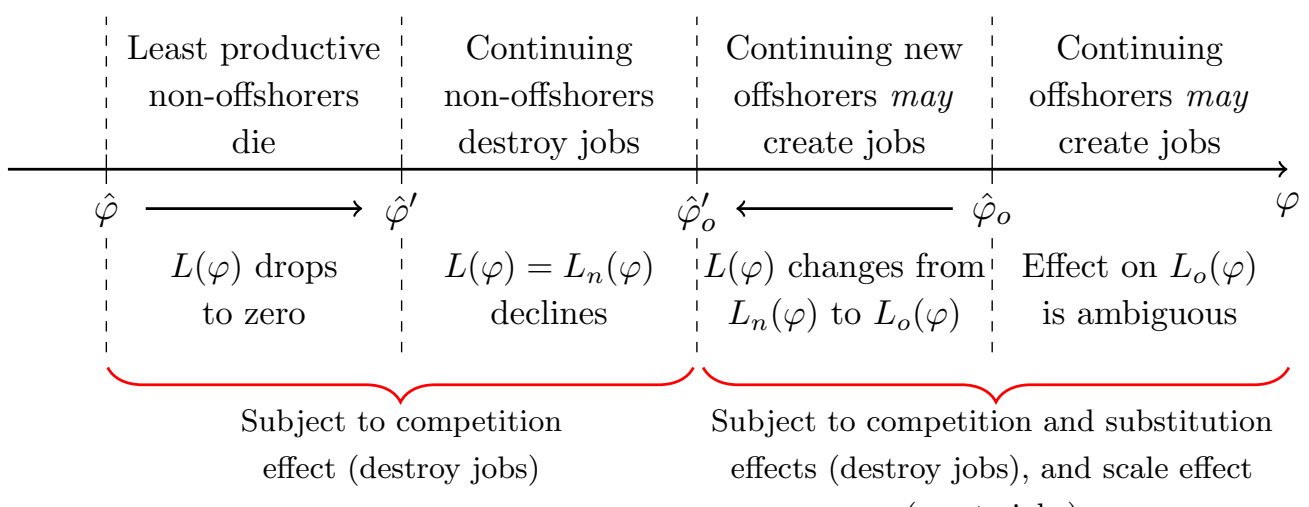

(create jobs)

Figure 2: A reduction in input trade costs and firm-level domestic employment

There are strong similarities between Figures 2 and 1 . The same three predictions emerge after a decline in $\lambda$ which were obtained earlier for a decline in $\tau$. Prediction 1 is related to the job destruction by firms with productivities between $\hat{\varphi}^{\prime}$ and $\hat{\varphi}_{o}$. Prediction 2 concerns the possible job creation by high-productivity firms, which in the model correspond to firms with productivities above $\hat{\varphi}_{o}$. Lastly, Prediction 3 is related to those firms between $\hat{\varphi}$ and $\hat{\varphi}^{\prime}$, which die after a reduction in $\lambda$.

\subsection{Intersectoral Linkage}

To bring the model of offshoring discussed above closer to the empirical exercise, let us put some structure on the inputs in the composite $M$, which are produced outside the firm boundary. Suppose there are $J$ differentiated-good industries and that firms in each industry buy inputs from all industries. In particular, for a firm in industry $j$ the composite input $M_{j}$ is given by

$$
M_{j}=\left(1 / \prod_{k=1}^{J} a_{k j}^{a_{k j}}\right) \prod_{k=1}^{J} X_{k}^{a_{k j}}, \quad \text { where } \quad \sum_{k=1}^{J} a_{k j}=1 \forall j \in J .
$$

That is, $M_{j}$ is combined using a Cobb-Douglas technology with the cost share of input $X_{k}$ being $a_{k j}$. Input $X_{k}$ is the CES composite of the varieties produced in industry $k$, which can be sourced domestically or offshored.

Let $P_{k}$ denote the domestic price of the composite good produced by industry $k$. Then, given (12) the cost of a unit of $M_{j}$ for a non-offshoring firm in industry $j$ is given by

$$
p_{M_{j}, n}=\prod_{k=1}^{J} P_{k}^{a_{k j}}
$$

determined. After a decline in $\lambda$, that model generates a job-relocation effect because the fraction of offshored inputs increases. In the model described here, the same effect can be achieved by allowing $\alpha$ in (6) to depend on $\lambda$. Importantly, expanding the current model to add a job-relocation effect will continue to generate Figure 2 and does not alter any of the three predictions we test below. 
Suppose the border price of offshored input from industry $k$ is $P_{k}^{*}$, but in addition, there is an iceberg trading cost such that $1+\tau_{k}$ units of the input must be shipped for one unit to arrive at the destination; the effective price of a unit of offshored input from industry $k$ is then $P_{k}^{*}\left(1+\tau_{k}\right)$. Therefore, similar to (13), the price of the composite offshored input $M_{j}$ for an offshoring firm from industry $j$ is

$$
p_{M_{j}, o}=p_{M_{j}}^{*} \prod_{k=1}^{J}\left(1+\tau_{k}\right)^{a_{k j}}, \text { where } p_{M_{j}}^{*}=\prod_{k=1}^{J}\left(P_{k}^{*}\right)^{a_{k j}}
$$

Compared to (7) - from the single differentiated-good industry case-note that $\prod_{k=1}^{J}\left(1+\tau_{k}\right)^{a_{k j}}$ is the analogue of $1+\lambda$. As before, for offshoring to be beneficial for a firm in industry $j$, we require $p_{M_{j}, o}<p_{M_{j}, n}$

Taking the $\log$ of both sides of $(14)$ and using the result that $\log \left(1+\tau_{k}\right) \approx \tau_{k}$, we obtain that $\log \left(p_{M_{j}, o}\right)-\log \left(p_{M_{j}}^{*}\right) \approx \lambda_{j}$, where

$$
\lambda_{j} \equiv \sum_{k=1}^{J} a_{k j} \tau_{k}
$$

is an aggregate measure of input trade costs for industry $j$. In our empirical exercise we construct industry-level input trade costs using (15). As in Amiti and Konings (2007), we use the inputoutput table to obtain the cost share of each input in each industry, $\left\{a_{k j}\right\}$. Note that any change in $\lambda_{j}$ resulting from a change in any $\tau_{k}$ will affect firm-level employment through the channels discussed above.

\section{Data}

This section presents facts about the manufacturing industry in the U.S. and California, discusses our data, and describes our measures of trade costs.

\subsection{The U.S. Manufacturing Employment and the California Data}

If we want to understand the relationship between trade costs and job flows in the United States, manufacturing is the key sector to study. According to data from the United States International Trade Commission (USITC), U.S. manufacturing imports accounted for about $92 \%$ of the U.S. total non-oil imports for each year from 1990 to 2008. In 2007, the size of U.S. manufacturing imports was $11.2 \%$ as proportion of GDP. ${ }^{8}$

Figure 3 presents general facts about the U.S. manufacturing industry. Figure 3a shows the evolution of the employment level and real GDP in manufacturing since 1949. The volatility of the

\footnotetext{
${ }^{8}$ Putting this number in perspective with respect to the three major trading partners of the U.S., $11.2 \%$ of the U.S. GDP in 2007 was equivalent - according to the World Economic Outlook of the International Monetary Fund-to $108 \%$ of Canada's GDP, $46 \%$ of China's GDP, and $151 \%$ of Mexico's GDP.
} 


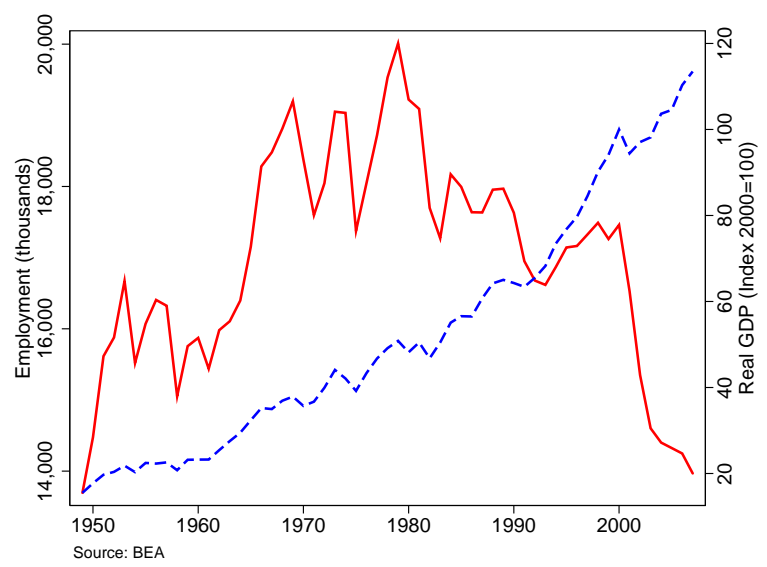

(a) Employment (solid) and real GDP (dashed)

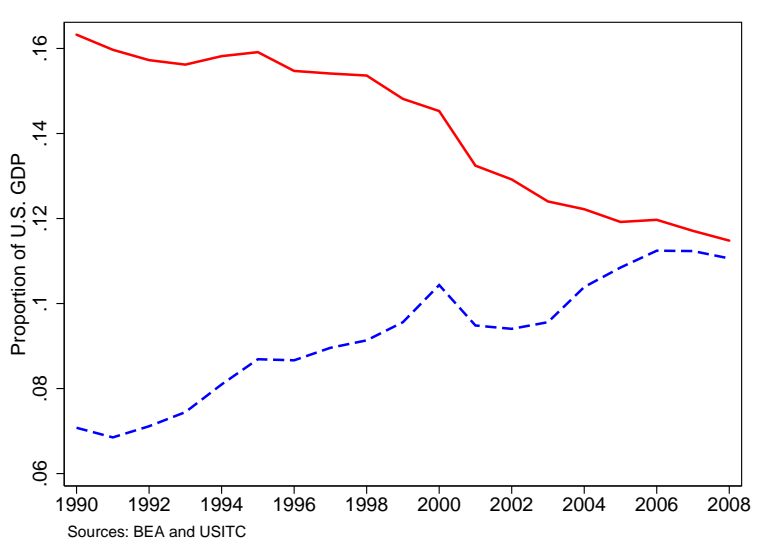

(b) Domestic production (solid) and imports (dashed)

Figure 3: The manufacturing industry in the U.S.

employment level is substantial. Moreover, from 2000 to 2003, the manufacturing industry suffered its largest employment change in a three-year period, with a loss of about 2.86 million jobs. ${ }^{9}$ Although this represents a loss of $16.4 \%$ of manufacturing jobs, the real GDP in the industry fell only about $1.8 \%$ over the period. By 2007 , even though the employment level had continued to decline at a moderate pace (nearly reaching its 1949 levels), real GDP was 13.5\% higher than in 2000. Therefore, the decline in the importance of manufacturing in total U.S. GDP - as observed in Figure $3 \mathrm{~b}$ - does not mean that U.S. manufacturing production is shrinking, but just that it is growing at a slower rate than other sectors of the economy. Figure $3 \mathrm{~b}$ shows, however, that manufacturing imports have increased dramatically as a proportion of the U.S. GDP since 1990, reaching more than $11 \%$ by 2008 (very close to the share of GDP of domestic manufacturing production).

In the rest of this subsection, first we present evidence of the high correlation between manufacturing employment in California and in the entire country; second, to verify the reliability of California's NETS data, we compare it to aggregate employment measures for California from the Quarterly Census of Employment and Wages (QCEW) of the Bureau of Labor Statistics (BLS); and third, using our data, we present some stylized facts about the evolution of the different components of job flows.

\subsubsection{The Manufacturing-Employment Correlation between California and the U.S.}

Although we do not have access to firm-level employment data for the entire country, we use an extract of the National Establishment Time Series (NETS) database, which contains the universe of establishments in California's manufacturing industry from 1992 to 2004. In the U.S., California

\footnotetext{
${ }^{9}$ For the entire labor force there was a loss of about 1.52 million jobs during the same period.
} 


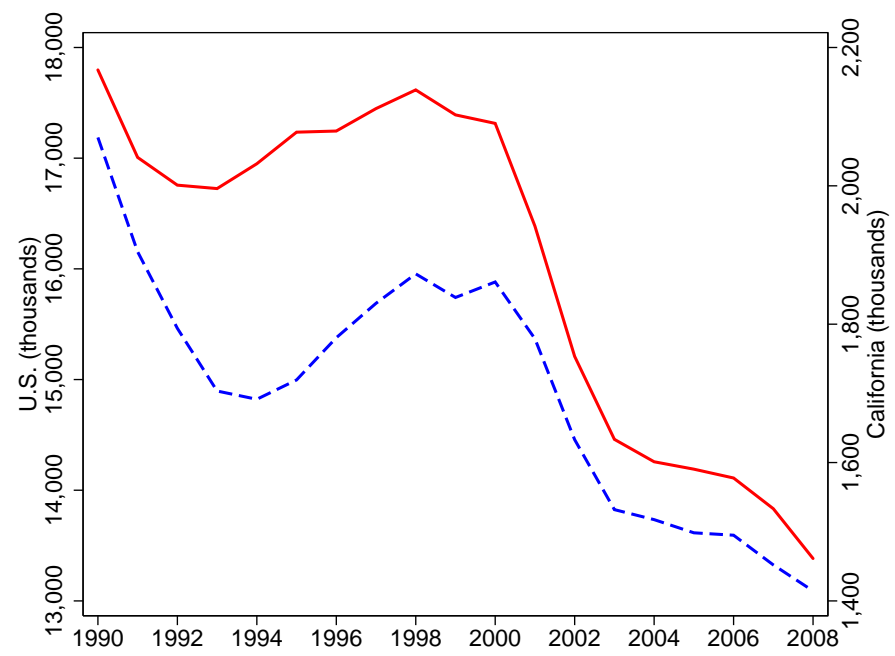

Figure 4: Manufacturing employment in California (dashed) and the U.S. (solid)

is the state with the largest economy and population. In 2007, the state accounted for $13.1 \%$ of the U.S. GDP and 12\% of the country's population, according to the Bureau of Economic Analysis (BEA) and the Census Bureau. ${ }^{10}$ It accounted for $11.3 \%$ of U.S. manufacturing production in 1990, and the share stood at $11 \%$ in 2008. In order for our empirical analysis on job flows to be representative of the U.S. economy, we must demonstrate that California's manufacturing employment is highly correlated with national manufacturing employment.

Using data from the QCEW, Figure 4 presents the national and California's manufacturing employment from 1990 to 2008. California's share of the U.S. manufacturing employment was about $11.6 \%$ in 1990 and $10.6 \%$ in 2008 . The correlation coefficient between California's and the U.S. employment-level series is 0.93. Moreover, the correlation coefficient between the series' first differences - the employment change from year to year - is 0.81. Hence, employment levels and employment changes in California's manufacturing industry track very well the national manufacturing employment.

The close relationship observed for aggregate manufacturing employment also appears at more disaggregated industry levels. Using QCEW data for 1992 and 2004, Figure 5 shows manufacturing employment in California and the U.S. at the three-digit NAICS level (21 manufacturing industries). If we remove the outlier in both panels, which corresponds to NAICS industry 334 (Computer and Electronic Product Manufacturing) which is disproportionately located in California, the correlations between California and the U.S. industry-level employment are 0.94 in 1992 and 0.89 in 2004-including industry 334 the correlations are, respectively, 0.83 and 0.74 . The correlations remain very high even at the six-digit NAICS level (409 manufacturing industries);

\footnotetext{
${ }^{10}$ The size of California's economy in 2007 would place it (based on the IMF's WEO database) as the eighth-largest economy in the world - just below Italy and above Spain, Canada, Brazil, and Russia.
} 


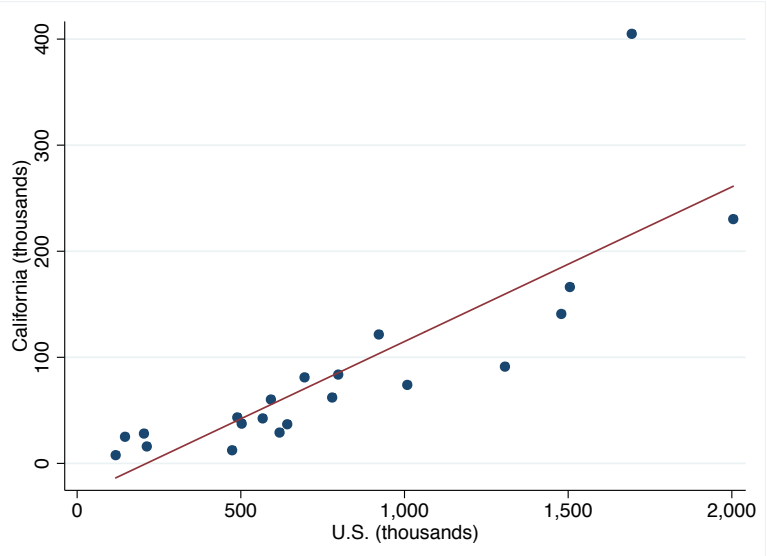

(a) 1992

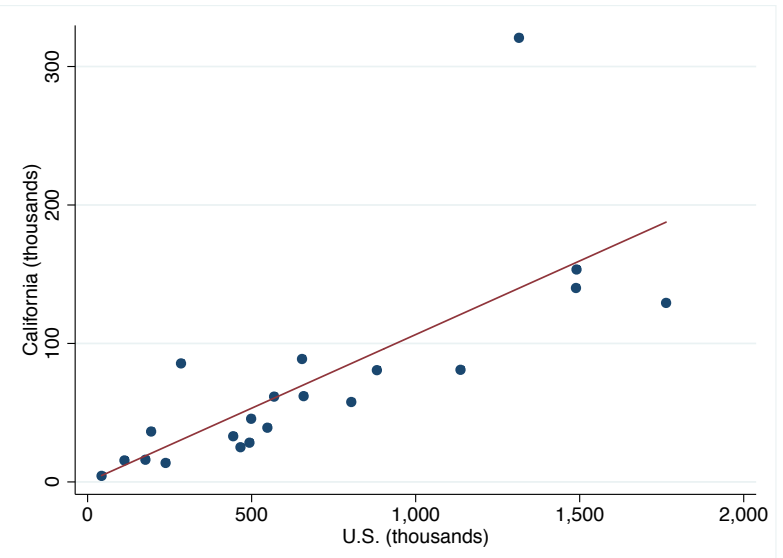

(b) 2004

Figure 5: Manufacturing employment at three-digit NAICS level: California versus the U.S.

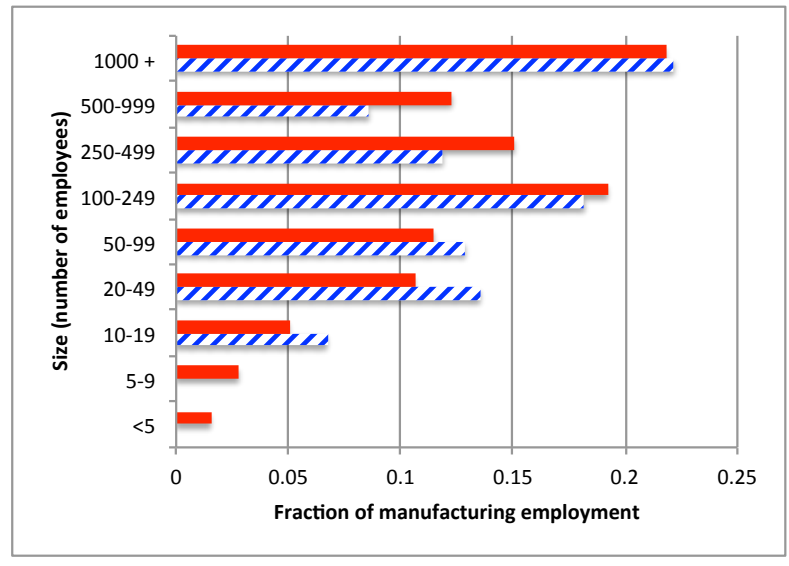

(a) 1992

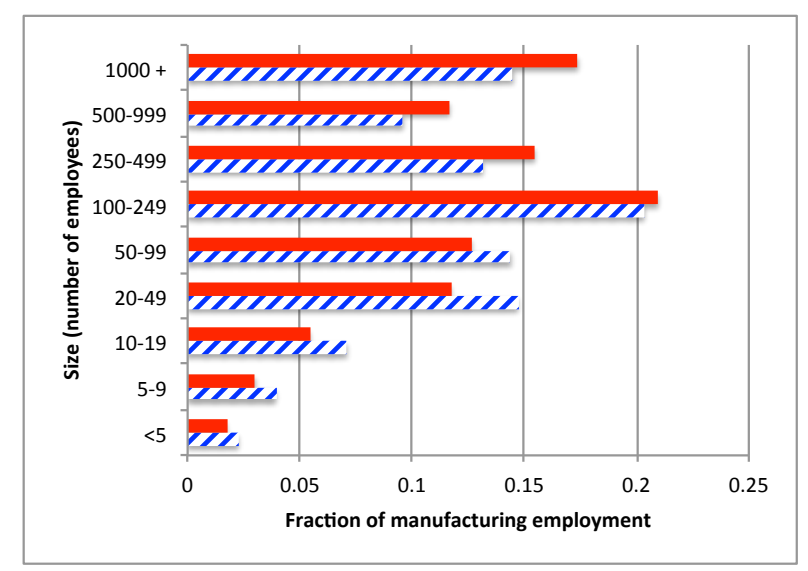

(b) 2004

Figure 6: Distribution of manufacturing employment by establishment size: California (hatched bars) and the U.S. (solid bars)

Figure C.1 in the Appendix presents manufacturing employment in California and the U.S. at the six-digit NAICS level, showing a correlation of 0.76 in 1992 and 0.72 in 2004.

If we classify manufacturing establishments by size according to their employment level, we also observe strong similarities between California and the entire country. Using QCEW data for the months of March 1992 and March 2004, Figure 6 shows the distribution of manufacturing employment by establishment size in the U.S. and California. Each establishment is classified into 1 of 9 categories according to its employment level, and each bar indicates the fraction of total manufacturing employment in that category. The QCEW started reporting employment levels for establishments below 10 employees in California in 2001, and hence, we have no bars for California for the two lowest categories in 1992; we know, however, that the sum of these two categories 


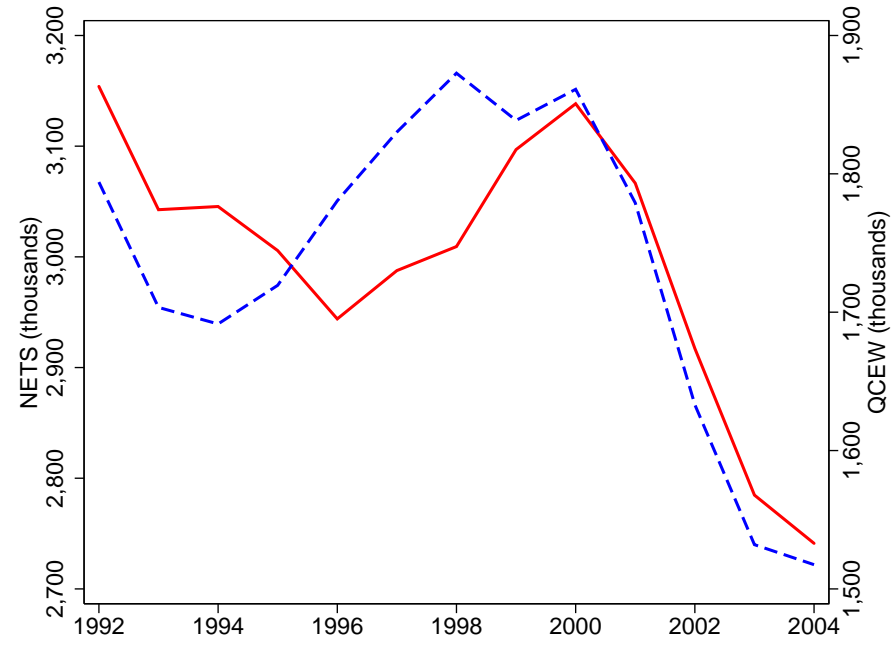

Figure 7: Manufacturing employment in California: NETS (solid) and QCEW (dashed)

accounts for $6 \%$ of manufacturing employment in that year. In both years, the figures show the same patterns and, in general, similar shares across categories. The main difference is that the share in manufacturing employment of establishments below 100 employees is higher in California.

Given the close relationship between California and U.S. manufacturing employment shown in this section, we are confident that the results we obtain from our empirical exercise below are representative of the effects of input and output trade costs on U.S. establishment-level job flows.

\subsubsection{On the Reliability of the NETS Data}

To verify the reliability of our job flows data, we compare California's manufacturing employment levels from the QCEW and the NETS. Figure 7 shows the two series from 1992 to 2004. The correlation is 0.82 for the employment levels and 0.68 for the first differences. Although they are highly correlated, there is a substantial difference between the total employment levels in the two series: the NETS data reports on average $73 \%$ more employees than the QCEW data. Neumark, Zhang, and Wall (2007) and Neumark, Wall, and Zhang (2011) provide an exhaustive assessment of the NETS database (relying mostly on the California extract of NETS we use) and investigate, among other things, the difference in total employment levels between NETS and the QCEW. They report that the difference arises because the BLS data excludes self-employed workers and proprietors, and because NETS has better coverage of small establishments. With respect to the lower correlation for employment changes, they find that there is some stickiness in the NETS data, and this is reflected in year-to-year changes. For three-year changes - which is the time frame we use in our benchmark empirical analysis - they obtain a correlation of 0.86 between the two series. 
Neumark, Wall, and Zhang (2011) also compare the NETS data against the Current Employment Statistics (CES) database of the BLS, and find an employment correlation between them of 0.99 at the county-by-industry level. Moreover, using California data on biotech companies, they show that NETS detects $88 \%$ of companies' births within a year; additionally, using Lexis-Nexis newspaper data, they show that NETS is also very accurate at tracking businesses relocations.

Haltiwanger, Jarmin, and Miranda (2013) provide a brief comparison of the Longitudinal Business Database (LBD) of the Census Bureau and the NETS database. ${ }^{11}$ They mention that LBD reports 7 million establishments in a typical year, while NETS report 14.7 million establishments in a typical year. They suggest that the difference is due to the fact that NETS includes nonemployer businesses, while LBD includes establishments with at least one paid employee - as mentioned above, NETS counts a proprietor as an employee. Importantly, nonemployer businesses generate revenue. Davis et al., 2009 discuss the importance of nonemployer businesses and give the first steps towards the creation of the Integrated Longitudinal Business Database (ILBD), which expands the LBD to include them.

To sum up, the NETS data is a reliable source for the analysis of job flows in the U.S. manufacturing industry. Section B in the Appendix presents some stylized facts about the evolution of job flows in our data.

\subsection{Trade Costs}

In our empirical analysis, the most important explanatory variables are industry-level input and final-good trade costs. In this section we explain how we construct these measures and describe the patterns they follow during our period of interest.

We use the updated U.S. trade database of Feenstra, Romalis, and Schott (2002) to construct input and final-good trade costs for 390 four-digit SIC manufacturing industries. As in Bernard, Jensen, and Schott (2006b), we compute each industry's final-good trade cost as the sum of the industry's average tariff rate and the industry's average international freight rate. ${ }^{12}$ That is, the final-good trade cost for industry $j$ in year $t, \tau_{j t}$, is defined as the ratio of duties collected by U.S. customs authorities plus freight costs to the free-on-board customs value of imports.

In section 2.1 we describe the effects of a decline in final-good trade costs that is symmetric for

\footnotetext{
${ }^{11}$ Haltiwanger, Jarmin, and Miranda (2013) compare their results on employment growth and firm size against the results of Neumark, Wall, and Zhang (2011). Important for the comparison of LBD and NETS, when running an specification without controlling for firm age (similar to the specification of Neumark, Wall, and Zhang, 2011), the estimation with the LBD data yields similar results to those of Neumark, Wall, and Zhang (2011) with the NETS data. The difference between the papers emerges when Haltiwanger, Jarmin, and Miranda (2013) expand the econometric specification to control for firm age, which Neumark, Wall, and Zhang (2011) do not do.

${ }^{12}$ To the extent that recent developments in transportation and communication technology have lowered trading costs, which are not captured by changes in tariffs, our trade cost measure - which includes transportation costsbetter captures changes in trade barriers.
} 
all trading partners (i.e., $\tau$ is the final-good trade cost for both domestic and foreign exporters). Empirically, our final-good trade cost measure corresponds to that of countries that export to the U.S. (it is based on U.S. imports). Unfortunately, we do not have access to duties and freight costs of U.S. exporters. Therefore, following Bernard, Jensen, and Schott, 2006b, we assume that the calculated (imports-based) final-good trade costs are also a good approximation for exporting costs of U.S. firms.

From equation (15) and following Amiti and Konings (2007), we construct the input trade cost for each industry as a weighted average of final-good trade costs. Then, the input trade cost for industry $j$ in year $t, \lambda_{j t}$, is given by

$$
\lambda_{j t}=\sum_{k} a_{k j} \tau_{k t},
$$

where the weight $a_{k j}$ is the ratio of industry $j$ 's input purchases from industry $k$ to the total input purchases of industry $j .{ }^{13}$ We compute the weights from the 1987 U.S. input-output table created by the Bureau of Economic Analysis (BEA). We use the 1987 table because, as we will see below, our analysis requires trade data since 1989 (three years before our first NETS year) and the first input-output table before 1989 is the one from 1987.

Two important remarks with respect to the input-trade-cost measure are in order: first, it is based on cost shares irrespective of whether inputs are domestic or imported; and second, we keep the weights constant over time. Regarding the first point, which is similar to the theoretical approach in section 2.3, Amiti and Konings (2007) highlight that this is the correct measure of input trade costs - as opposed to a measure with weights based on shares of imported inputsbecause it gives more weight to the costs of inputs that are used more intensively in an industry, whether those inputs are imported or not. ${ }^{14}$ Regarding the second point, although input-output tables are calculated every five years for the U.S. and it would be possible to link them using interpolation methods, keeping the weights constant over time prevents an endogeneity bias caused by the movements in opposite directions of final-good trade costs and weights. ${ }^{15}$

Figure 8 shows the relationships between our industry-level trade costs in the initial year, 1989,

\footnotetext{
${ }^{13}$ Since the work of Amiti and Konings (2007), this measure of input trade costs has become standard in studies that attempt to separate the effects of input trade costs and final-good trade costs. It has been used, for example, by Amiti and Davis (2011), Goldberg, Khandelwal, Pavcnik, and Topalova (2010), and Yu (2014).

${ }^{14}$ As an example, Amiti and Konings (2007) point out that if "an industry is intensive in rubber usage, the relevant tariff is the tariff on rubber, irrespective of whether rubber is imported."

${ }^{15}$ To illustrate this point, consider an extreme example of an industry $A$ that employs inputs from industries $B$ and $C$, with respective cost shares of 0.6 and 0.4 . If we assume that the initial tariffs are 0.5 for industry $B$ and 0.1 for industry $C$, the initial input tariff rate is 0.34 . Now suppose that when the tariff for industry $B$ declines to 0.4 , its cost share in industry $A$ rises to 0.9 . If we keep the weights constant, the new input tariff is 0.28 , reflecting the decline in input trade costs. On the other hand, if we use the new cost shares, the new input tariff would be 0.37, which is above the original input tariff - missing entirely the decline in trade costs. Amiti and Konings (2007), Amiti and Davis (2011), Goldberg, Khandelwal, Pavcnik, and Topalova (2010), and Yu (2014) also keep the weights constant over time.
} 


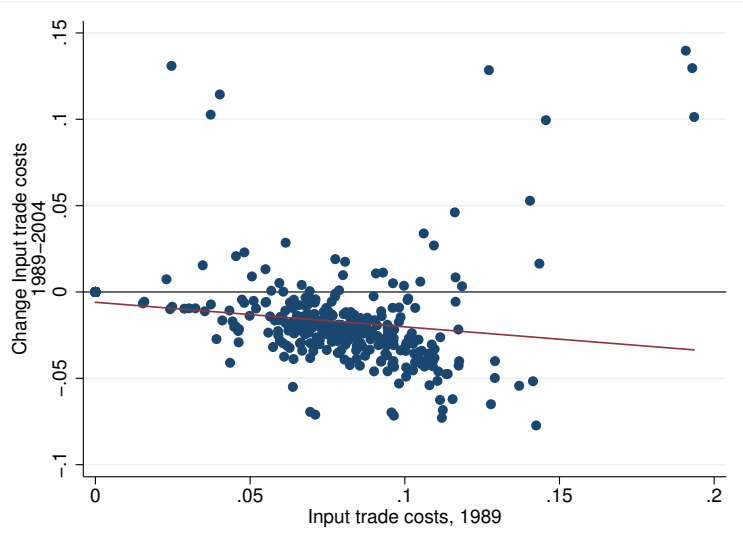

(a) Input trade cost

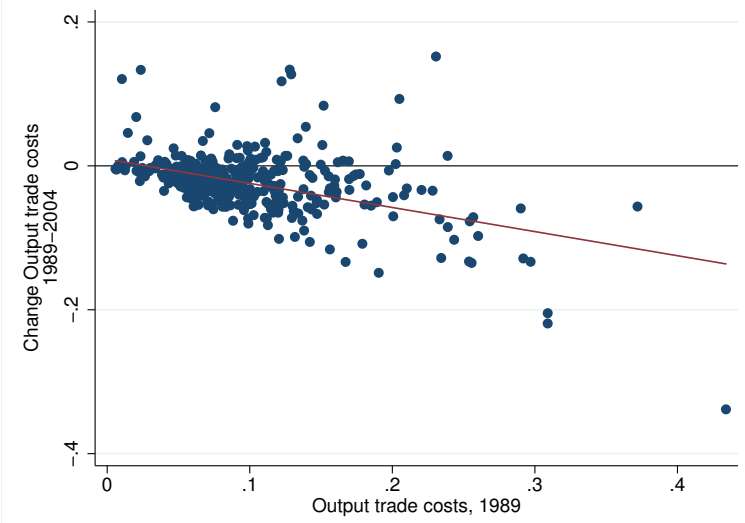

(b) Final-good trade cost

Figure 8: Trade cost changes across 4-digit SIC industries relative to initial levels

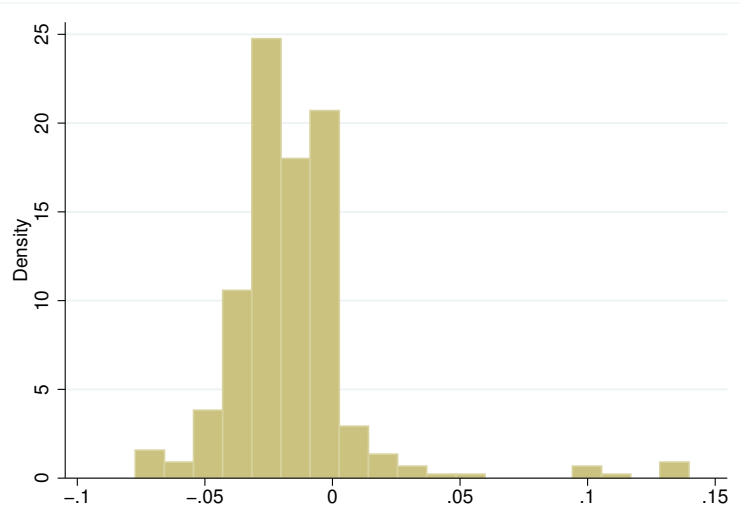

(a) Input trade cost changes

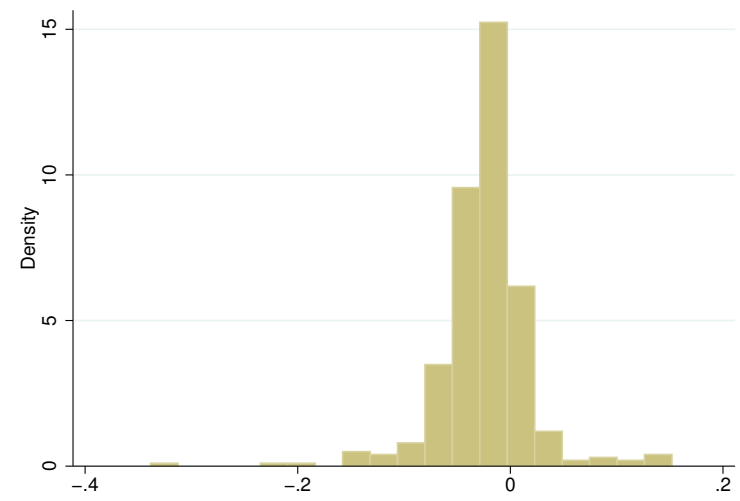

(b) Final-good trade cost changes

Figure 9: Distribution of trade cost changes across 4-digit SIC industries (1989-2004)

and their changes over our period of study, 1989-2004. Note that in the initial year, input trade costs range between 0 and 0.2 , with most of them located in the $[0.6, .12]$ range, while final-good trade costs range between 0 and 0.43 , with most of them located in the $[0.03,0.15]$ range. Most of the changes in both plots are negative, which indicates a period of reduction in barriers to both input and final-good trade. Moreover, the negative slopes indicate that the sharpest declines in both trade cost measures correspond to the industries with higher initial trade costs. Note that changes over the period are mostly in the $[-0.06,-0.01]$ range for input trade costs, and between the $[-0.1,0.01]$ range for final-good trade costs. Figure 9 confirms this by showing histograms of the input and final-good trade-cost changes.

Although the initial trade-cost rates and their changes seem rather modest, we argue that they provide sufficient information and variation to identify the effects on job flows of reductions in 


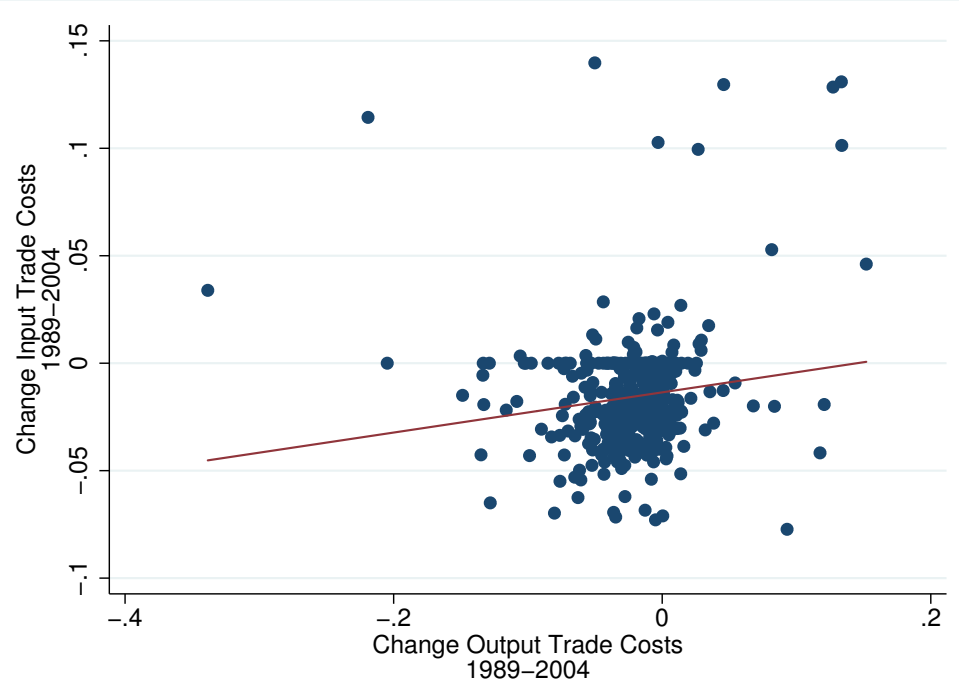

Figure 10: Change in input trade costs vs change in final-good trade costs (1989-2004)

barriers to input and final-good trade. There are at least two reasons for this to be the case. As mentioned by Trefler (2004), as long as there is a positive correlation between tariff and nontariff barriers, a decline in a tariff-based trade cost measure would capture the general extent of trade liberalization. Trefler (2004) uses U.S. and Canadian tariffs in his plant-level employment regressions and argues that even if small, these tariffs are positively related to non-tariff barriers and hence, they capture the essence of the U.S.-Canada free trade agreement. Moreover, while average tariffs for the U.S. are low, Yi (2003) shows that the possibility of vertical specialization creates a multiplier effect that is reflected in huge increases in trade volumes even for small declines in tariffs.

Interestingly, the correlation between changes in input trade costs and changes in final-good trade costs is very low in our data. Figure 10 shows the 1989-2004 changes in input and final-good trade costs for each industry: the correlation between the two measures is only 0.15 . Therefore, our empirical analysis in the following sections is able to separately identify the effects of the two types of trade cost changes on job flows and thus, to correctly gauge the relative importance of each of them.

\section{Intensive-Margin Estimation}

In this section we estimate the effects of input and final-good trade costs on establishment-level expansions and contractions of employment to verify if predictions 1 and 2 mentioned in the Introduction hold. We first present the econometric model, then we describe the establishment-level variables and the industry-level controls, and lastly we show our estimation results. 


\subsection{Econometric Model}

Predictions 1 and 2 state that a reduction in trade costs causes job destruction in the least productive firms, and possible job creation in the most productive firms - these are firm-level predictions at the intensive margin. Let $\mathbb{E}_{i j t}$ denote the employment level of establishment $i$, in four-digit SIC industry $j$, at time $t$. Our starting point is the following linearized firm-level labor demand function:

$$
E_{i j t}=\beta^{\lambda} \lambda_{j t-1}+\beta^{\tau} \tau_{j t-1}+\gamma^{\lambda} \lambda_{j t-1} \Phi_{i j}+\gamma^{\tau} \tau_{j t-1} \Phi_{i j}+\theta_{i}+\nu_{i} t+\varsigma_{s t}+\varpi \Psi_{i t}+\kappa \Upsilon_{j t-1}+\varepsilon_{i j t},
$$

where $E_{i j t}=\log \mathbb{E}_{i j t}, \lambda_{j t-1}$ and $\tau_{j t-1}$ are the lagged levels of input and final-good trade costs in industry $j, \Phi_{i j}$ is the productivity of establishment $i$ relative to its peers in industry $j, \theta_{i}$ is an establishment-specific fixed effect that measures unobserved constant heterogeneity (e.g. the establishment's productivity, $\Phi_{i j}$, is included in $\left.\theta_{i}\right), \nu_{i} t$ accounts for any idiosyncratic trend in each establishment's employment, $\varsigma_{s t}$ accounts for industry-time fixed effects (with $s$ denoting the twodigit SIC industry of the establishment), $\Psi_{i t}$ is a vector of establishment characteristics, $\Upsilon_{j t-1}$ is a vector of lagged industry-level characteristics, and $\varepsilon_{i j t}$ is the error term. The purpose of including a lag in some of the right-hand side variables in equation (16) is simply to prevent situations in which a change in the dependent variable happens before a change in one or more of the explanatory variables. ${ }^{16}$

Our parameters of interest are $\beta^{\lambda}, \beta^{\tau}, \gamma^{\lambda}$, and $\gamma^{\tau}$ because they characterize the employment response of an establishment - given its productivity - to a change in input or final-good trade costs. Given that the dependent variable is in logs and our trade cost measures are rates, the interpretation of these parameters is straightforward. For example, the semi-elasticity of employment with respect to input trade costs for an establishment with relative productivity $\Phi$ is given by

$$
\beta^{\lambda}+\gamma^{\lambda} \Phi
$$

Hence, after a one percentage point increase in the input trade cost (e.g. from 0.03 to 0.04 ), the employment of an establishment with productivity $\Phi$ changes by $\beta^{\lambda}+\gamma^{\lambda} \Phi$ percent. The same is true for a change in final-good trade costs, and therefore, we can compare the input trade cost semielasticity of an establishment with productivity $\Phi$ against $\beta^{\tau}+\gamma^{\tau} \Phi$, which is that establishment's final-good trade cost semi-elasticity.

An important concern is that establishment-level employment and possibly trade costs are nonstationary. Therefore, the proper estimation of our parameters of interest requires that we estimate

\footnotetext{
${ }^{16}$ For example, a change in employment might happen in February, while a change in trade costs might occur in November of the same year. Without a lag, these changes would be treated as contemporaneous even though the trade-cost change occurs later. We follow the same reasoning in all the regression specifications that appear in the rest of the paper.
} 
the model in first differences. Hence, taking the first difference of equation (16), the econometric model to estimate is

$$
\dot{E}_{i j t}=\beta^{\lambda} \dot{\lambda}_{j t-1}+\beta^{\tau} \dot{\tau}_{j t-1}+\gamma^{\lambda} \dot{\lambda}_{j t-1} \Phi_{i j}+\gamma^{\tau} \dot{\tau}_{j t-1} \Phi_{i j}+\nu_{i}+\dot{\varsigma}_{s t}+\varpi \dot{\Psi}_{i t}+\kappa \dot{\Upsilon}_{j t-1}+\dot{\varepsilon}_{i j t},
$$

where a "dot" denotes the first difference of a variable (note that $\theta_{i}$ vanishes). The dependent variable, $\dot{E}_{i j t}=E_{i j t}-E_{i j t-1}$, is the percentage change in establishment- $i$ 's employment from $t-1$ to $t$. Note that the estimation of (17) will not include establishments at the time they are born nor at the time they die: if establishment $i$ is born at time $t, E_{i j t-1}$ does not exist and hence, $\dot{E}_{i j t}$ is undefined; on the other hand, if establishment $i$ dies at time $t, \mathbb{E}_{i j t}$ drops to zero and hence $E_{i j t}=\log \mathbb{E}_{i j t}$ and $\dot{E}_{i j t}$ become undefined.

Equation (17) gives net intensive margin responses. Additionally - and following closely the literature on job flows (see, for example, Davis, Haltiwanger, and Schuh, 1996) - we can decompose $\dot{E}_{i j t}$ into two intensive-margin job flow components: expansions and contractions. Let $e_{i j t}$ represent the rate of job creation by expansion for establishment $i$, from industry $j$, between $t-1$ and $t$. Similarly, let $c_{i j t}$ denote the establishment's rate of job destruction by contraction. Given $\dot{E}_{i j t}$, we define them as

$$
\begin{aligned}
e_{i j t} & =\max \left(\dot{E}_{i j t}, 0\right), \\
c_{i j t} & =\max \left(-\dot{E}_{i j t}, 0\right),
\end{aligned}
$$

where $\dot{E}_{i j t} \equiv e_{i j t}-c_{i j t}$. Thus, we can split (17) as follows:

$$
\begin{aligned}
& e_{i j t}=\beta_{e}^{\lambda} \dot{\lambda}_{j t-1}+\beta_{e}^{\tau} \dot{\tau}_{j t-1}+\gamma_{e}^{\lambda} \dot{\lambda}_{j t-1} \Phi_{i j}+\gamma_{e}^{\tau} \dot{\tau}_{j t-1} \Phi_{i j}+\nu_{i}^{e}+\dot{\zeta}_{s t}^{e}+\varpi_{e} \dot{\Psi}_{i t}+\kappa_{e} \dot{\Upsilon}_{j t-1}+\dot{\varepsilon}_{i j t}^{e}, \\
& c_{i j t}=\beta_{c}^{\lambda} \dot{\lambda}_{j t-1}+\beta_{c}^{\tau} \dot{\tau}_{j t-1}+\gamma_{c}^{\lambda} \dot{\lambda}_{j t-1} \Phi_{i j}+\gamma_{c}^{\tau} \dot{\tau}_{j t-1} \Phi_{i j}+\nu_{i}^{c}+\dot{\zeta}_{s t}^{c}+\varpi_{c} \dot{\Psi}_{i t}+\kappa_{c} \dot{\Upsilon}_{j t-1}+\dot{\varepsilon}_{i j t}^{c},
\end{aligned}
$$

where the model in (17) is equivalent to the difference between models (18) and (19) so that

$$
\beta^{\lambda} \equiv \beta_{e}^{\lambda}-\beta_{c}^{\lambda}, \quad \beta^{\tau} \equiv \beta_{e}^{\tau}-\beta_{c}^{\tau}, \gamma^{\lambda} \equiv \gamma_{e}^{\lambda}-\gamma_{c}^{\lambda}, \gamma^{\tau} \equiv \gamma_{e}^{\tau}-\gamma_{c}^{\tau}
$$

Our analysis below estimates equations (17), (18), and (19).

\subsection{Description of Variables}

As mentioned above, our establishment-level data is an extract of NETS - a longitudinal establishment level national database - that includes annual data for every establishment that was located in California in any year between 1992 and 2004. Our trade cost data was constructed from the updated database of Feenstra, Romalis, and Schott (2002) for the period 1989-2004. In addition, we also obtain industry-level variables from the NBER productivity database (see Bartelsman and Gray, 1996). 


\subsubsection{Job Flows}

In NETS, each establishment has a unique identifier and is carefully followed through the years. ${ }^{17} \mathrm{~A}$ distinguishing feature of NETS is that it is not a representative sample of business establishments, but the universe of them. Each establishment is classified by NETS according to its primary, secondary, and tertiary Standard Industrial Classification (SIC) code at the eight-digit level. We use the primary SIC code to match each establishment to a unique industrial sector at the four-digit SIC level. We drop from our database all the non-manufacturing establishments. ${ }^{18}$ In the end, each establishment in this analysis belongs to one of 390 four-digit SIC manufacturing industries. For each establishment we create job-flow and productivity variables.

The job-flow variables $\left(\dot{E}_{i j t}, e_{i j t}\right.$, and $\left.c_{i j t}\right)$ are created from reported employment levels. For our benchmark regressions we assume a three-year difference between $t-1$ and $t$. The motivation for using three-year differences is twofold: first, it accounts for the lagged response of firm-level employment to changes in trade costs, and second, it considers the apparent stickiness in the NETS data mentioned in section 3.1.2. Therefore, the job-flow variables in the benchmark regressions only use data for the years $1992,1995,1998,2001$, and $2004 .{ }^{19}$ In section 6 , however, we perform two robustness checks that re-estimate equations (17), (18), and (19) using all available data: in section 6.1 we use one-year differences, and in section 6.4 we use three-year overlapping windows (19921995, 1993-1996, 1994-1997, up to 2001-2004).

\subsubsection{Relative Productivity}

The three predictions we test in this paper mention that the effect of trade costs on firm-level job flows depends on each firm's productivity level. To verify this empirically, we require a variable measuring the relative productivity of each establishment. To construct this measure we rely on two characteristics of the recent theoretical literature on trade with heterogeneous firms spanned by the models of Bernard, Eaton, Jensen, and Kortum (2003) and Melitz (2003): (i) each firm has a constant level of efficiency or productivity, and (ii) firm-level productivity and size are positively related. For our empirical purposes, we interpret (i) as requiring a constant ordering of firms by

\footnotetext{
${ }^{17}$ In our dataset, an establishment is tracked all the years it is active as long as it was located in California for one or more years.

${ }^{18}$ As we should expect, employment changes in the traded sector of the economy have a counterpart in the nontraded sector. Ebenstein, Harrison, McMillan, and Phillips (2013) explore the mechanism of labor migration from the traded to the non-traded sector and its impact on wages.

${ }^{19}$ Given the years used, there are cases of establishments that existed but that will never appear in the benchmark regressions (e.g., an establishment that is born in 1996 and that dies in 1997 or 1998). Other establishments will only appear in the death regressions even if they had expansions or contractions before dying. For example, an establishment that is born in 1996 but dies in 2000, appears for the first time (in the benchmark regressions' data) in 1998 but by 2001 is already dead, so it does not appear in the intensive-margin regressions (it appears as a death for the 1998-2001 period in the death regression).
} 
productivity; that is, every firm throughout its lifetime keeps the same ranking of productivity with respect to its industry peers - there is substantial evidence showing that productivity differentials across firms are very persistent (for a survey, see Bartelsman and Doms, 2000). On the other hand, we rely on (ii) to create our productivity ranking of firms based on establishment-level sales - within a narrowly defined industry (as in our case with four-digit SIC disaggregation) more productive firms should have larger sales.

A common productivity measure in empirical papers is sales per worker. With offshoring possibilities, that measure is not appropriate for our empirical exercise. To see this, consider two firms, $A$ and $B$, with the same number of workers but with different levels of sales; in particular, firm $A$ has twice the sales of firm $B$. If the firms use only domestic labor, a measure of productivity using total sales and a measure of productivity using sales per worker will yield the same result: firm $A$ is twice as productive as firm $B$. Suppose now that offshoring is possible and firm $B$ uses half domestic labor, and half foreign labor. In this case, the sales-per-worker productivity measure (which is calculated using only domestic labor in the denominator-typically, the amount of hired foreign labor is unknown) yields the wrong result of identical productivities for firm $A$ and firm B. ${ }^{20}$

The steps to obtain the relative-productivity measure of each establishment that appears in our NETS manufacturing data are as follows. For establishment $i$ in industry $j$ we first calculate its real sales for every year it appears in the data - from the NBER productivity database, we use the four-digit SIC price index of shipments to deflate nominal sales. Then we calculate the average real sales of the establishment using all the years the establishment was observed in the database. After doing the same for each establishment of industry $j$, we rank them from the lowest to the highest average real sales. Lastly, we map this ranking to the $(0,2)$ range, so that $\Phi_{i j} \in(0,2)$, taking the value of 1 for the establishment with the median value of average real sales in industry $j$. This variable is symmetric, with the lowest-productivity establishments in the industry taking values close to zero, and the highest-productivity establishments taking values close to $2 .^{21}$

\footnotetext{
${ }^{20}$ It also common in the empirical literature to use a productivity measure based on establishment-level total factor productivity. Unfortunately, though good at tracking establishments' employment levels and sales, NETS provides few variables on establishments' characteristics. In particular, NETS does not report either capital stock or investment levels. Also, we cannot calculate a value-added measure of productivity because we do not have data on establishments' materials consumption.

${ }^{21}$ An alternative would be to use a ranking based on establishments' sales or employment for the first year they appear in the data. However, this measure would be severely biased in favor of older firms. A well established fact is that firms grow over time (see, for example, Cabral and Mata, 2003), and hence, firms that appear in the data from the beginning (since 1992) would be given in general a higher ranking than firms being born afterwards, even if the newer firms were more productive. When they are born, firms tend to start with few employees and small sales. By using average real sales over all the years that each firm appears in the data, our measure reduces the age-bias effect and takes into account that a firm's productivity takes some time to be reflected in the firm's size. See also the discussion of Davis, Haltiwanger, and Schuh (1996) for the negative and positive biases introduced by using either the initial or final employment as a measure of size. As in our case, they suggest an average measure to mitigate the
} 
We are not the first to take advantage of the theoretical monotonic relationship between firmlevel productivity and sales for an empirical application. For example, Verhoogen (2008) uses log domestic sales (deviation from industry means) to proxy for plant-level productivity. Likewise, Arkolakis (2010) uses the theoretical result of a positive relationship between productivity and sales percentiles of firms selling in the same market to construct a measure of relative productivity for French firms. Very similar to our approach, he ranks French firms selling in the same market according to their sales, and then maps the ranking to the interval $(0,1){ }^{22}$

In our case we map the sales ranking to the interval $(0,2)$, which simplifies the interpretation of our parameters of interest. For example, consider the semi-elasticity of job expansions with respect to input trade costs for an establishment with productivity $\Phi: \beta_{e}^{\lambda}+\gamma_{e}^{\lambda} \Phi$. After a one percentage point increase in input trade costs, job expansions change by about $\beta_{e}^{\lambda}$ percent for the least productive firm, by $\beta_{e}^{\lambda}+\gamma_{e}^{\lambda}$ percent for the median firm, and by about $\beta_{e}^{\lambda}+2 \gamma_{e}^{\lambda}$ percent for the most productive firm.

\subsubsection{Other Variables}

In section 3.2 we described the construction of input and final-good trade costs. To estimate the econometric models in (17), (18), and (19) we use lagged changes in trade costs. In the benchmark regressions these changes are over three years and therefore, they use trade cost data for the years 1989, 1992, 1995, 1998, and 2001. In the robustness section we use the rest of the years in the regressions with one-year differences (section 6.1) and three-year overlapping windows (section 6.4).

Our models also include establishment-level fixed effects $\left(\nu_{i}, \nu_{i}^{e}\right.$, and $\left.\nu_{i}^{c}\right)$ and industry-time fixed effects $\left(\dot{\zeta}_{s t}, \dot{\zeta}_{s t}^{e}\right.$, and $\left.\dot{\zeta}_{s t}^{c}\right)$. The former control for establishment-level idiosyncratic trends in employment, while the latter control for variation over time across two-digit SIC industries to capture relevant but hard to measure industry shocks (e.g., technological progress or changes in demand biased toward certain industries) along with aggregate shocks (e.g., changes in monetary policy or in the exchange rate).

Given that firms grow over time (see Cabral and Mata, 2003), we include the log age as an additional source of heterogeneity at the establishment level; that is, our estimation includes $\dot{\Psi}_{i t}=\log \left(\mathrm{Age}_{i t}\right)$. The vector $\dot{\Upsilon}_{j t-1}$ includes variables that capture observed industry-level heterogeneity. The omission of such variables may lead to overstate the trade cost effect if the industries that experience larger changes in trade costs are more affected by sectoral shocks. With the aim of controlling for changes over time of sectoral-level shocks, we include in $\dot{\Upsilon}_{j t-1}$ the lagged log bias.

${ }^{22}$ Arkolakis and Muendler (2011) apply the same approach in their study of multi-product Brazilian exporters. For all Brazilian firms selling in the same market and with a minimum product-scope level, they approximate their relative productivities by calculating their sales percentiles. 
Table 1: Intensive-Margin Estimation without Productivity Interactions

\begin{tabular}{|c|c|c|c|c|c|c|}
\hline \multicolumn{7}{|c|}{ Dependent variable (at time $t$ ) indicated in columns } \\
\hline \multirow{2}{*}{ Regressor (at $t-1$ ) } & \multicolumn{2}{|c|}{$\begin{array}{c}\text { Job } \\
\text { expansions } \\
(e) \\
\end{array}$} & \multicolumn{2}{|c|}{$\begin{array}{c}\text { Job } \\
\text { contractions } \\
(c) \\
\end{array}$} & \multicolumn{2}{|c|}{$\begin{array}{c}\text { Net intensive } \\
\text { margin } \\
(\dot{E} \equiv e-c)\end{array}$} \\
\hline & $(1)$ & $(2)$ & $(3)$ & $(4)$ & (5) & $(6)$ \\
\hline$\triangle($ Input trade cost $)$ & $\begin{array}{c}-0.014 \\
(0.142)\end{array}$ & $\begin{array}{c}0.007 \\
(0.144)\end{array}$ & $\begin{array}{c}0.052 \\
(0.112)\end{array}$ & $\begin{array}{c}0.072 \\
(0.113)\end{array}$ & $\begin{array}{c}-0.065 \\
(0.200)\end{array}$ & $\begin{array}{l}-0.065 \\
(0.201)\end{array}$ \\
\hline$\triangle($ Final-good trade cost $)$ & $\begin{array}{c}0.103 \\
(0.076)\end{array}$ & $\begin{array}{c}0.114 \\
(0.077)\end{array}$ & $\begin{array}{c}0.050 \\
(0.079)\end{array}$ & $\begin{array}{c}0.054 \\
(0.081)\end{array}$ & $\begin{array}{c}0.053 \\
(0.112)\end{array}$ & $\begin{array}{c}0.060 \\
(0.113)\end{array}$ \\
\hline Industry-level controls & No & Yes & No & Yes & No & Yes \\
\hline Observations & 219,593 & 219,593 & 219,593 & 219,593 & 219,593 & 219,593 \\
\hline Establishments & 88,606 & 88,606 & 88,606 & 88,606 & 88,606 & 88,606 \\
\hline
\end{tabular}

Notes: All regressions include establishment-level fixed effects, industry-time fixed effects (defined at the two-digit SIC level), and the establishment's log age. Industry-level controls (at four-digit SIC level) are the lagged log difference of: the price and value of shipments, the price of materials, total factor productivity, and the industry's employment level. Robust standard errors (in parentheses) clustered at the four-digit SIC industry level. The coefficients are statistically significant at the $* 10 \%, * * 5 \%$, or $* * * 1 \%$ level.

difference of the following (four-digit SIC) industry-level variables: the price and value of shipments, the price of materials, total factor productivity, and the industry's employment level. All the industry-level controls in $\dot{\Upsilon}_{j t-1}$ come from the NBER productivity database of Bartelsman and Gray (1996) (updated through 2004).

\subsection{Results}

It is essential to account for establishment heterogeneity to correctly estimate the effects of input and final-good trade costs on establishment-level employment. To highlight this point, we first estimate models (17), (18), and (19) under the restriction that heterogeneity does not matter; that is, we impose the constraints $\gamma^{\lambda}=\gamma_{e}^{\lambda}=\gamma_{c}^{\lambda}=\gamma^{\tau}=\gamma_{e}^{\tau}=\gamma_{c}^{\tau}=0$.

Table 1 presents the fixed-effects panel regression results for the restricted models. The panel includes 88,606 establishments and four three-year periods: 1992-1995, 1995-1998, 1998-2001, and 2001-2004 (the lagged explanatory variables include 1989-1992). We report robust standard errors clustered at the four-digit SIC industry level. Given the equivalence between the models' parameters described in (20), the estimated coefficients for the net-intensive-margin regression are identical to the difference between coefficients of the job-expansion and job-contraction regressions. No matter the specification, none of the coefficients on input or final-good trade costs is statistically significant. This would lead to the erroneous conclusion that reductions in input and final-good trade costs have no effect on establishment-level employment outcomes. 
Table 2: Intensive-Margin Estimation and Productivity

\begin{tabular}{lcccccc}
\hline \hline Dependent variable (at time $t$ ) indicated in columns & \multicolumn{2}{c}{$\begin{array}{c}\text { Job } \\
\text { expansions } \\
(\boldsymbol{e})\end{array}$} & $\begin{array}{c}\text { Job } \\
\text { contractions } \\
(\boldsymbol{c})\end{array}$ & $\begin{array}{c}\text { Net intensive } \\
\text { margin } \\
(\dot{\boldsymbol{E}} \equiv \boldsymbol{e}-\boldsymbol{c})\end{array}$ \\
\cline { 2 - 7 } Regressor (at $\boldsymbol{t}-\mathbf{1})$ & $(1)$ & $(2)$ & $(3)$ & $(4)$ & $(5)$ & $(6)$ \\
\hline & & & & & & \\
& $1.252^{* * *}$ & $1.272^{* * *}$ & $-0.682^{* * *}$ & $-0.663^{* * *}$ & $1.934^{* * *}$ & $1.935^{* * *}$ \\
$\triangle($ Input trade cost) & $(0.441)$ & $(0.444)$ & $(0.228)$ & $(0.226)$ & $(0.603)$ & $(0.603)$ \\
& $-1.161^{* * *}$ & $-1.159^{* * *}$ & $0.673^{* * *}$ & $0.674^{* * *}$ & $-1.834^{* * *}$ & $-1.833^{* * *}$ \\
$\times($ Relative Productivity) & $(0.368)$ & $(0.368)$ & $(0.199)$ & $(0.199)$ & $(0.506)$ & $(0.505)$ \\
$\triangle($ Final-good trade cost) $)$ & $0.651^{* * *}$ & $0.661^{* * *}$ & -0.187 & -0.181 & $0.838^{* * *}$ & $0.842^{* * *}$ \\
& $(0.142)$ & $(0.144)$ & $(0.160)$ & $(0.162)$ & $(0.267)$ & $(0.269)$ \\
$\times($ Relative Productivity) & $-0.499^{* * *}$ & $-0.498^{* * *}$ & $0.215^{*}$ & $0.214^{*}$ & $-0.714^{* * *}$ & $-0.712^{* * *}$ \\
& $(0.140)$ & $(0.139)$ & $(0.112)$ & $(0.112)$ & $(0.216)$ & $(0.216)$ \\
Industry-level controls & No & Yes & No & Yes & No & Yes \\
Observations & 219,593 & 219,593 & 219,593 & 219,593 & 219,593 & 219,593 \\
Establishments & 88,606 & 88,606 & 88,606 & 88,606 & 88,606 & 88,606 \\
\hline \hline
\end{tabular}

Notes: All regressions include establishment-level fixed effects, industry-time fixed effects (defined at the two-digit SIC level), and the establishment's log age. Industry-level controls (at four-digit SIC level) are the lagged $\log$ difference of: the price and value of shipments, the price of materials, total factor productivity, and the industry's employment level. Robust standard errors (in parentheses) clustered at the four-digit SIC industry level. The coefficients are statistically significant at the *10\%, ${ }^{*} 5 \%$, or ***1\% level.

Table 2 presents the estimation results for the unrestricted models. The results are widely different compared to those in Table 1. Comparing the specifications with and without industry controls, note that they yield coefficients of interest that are similar in magnitude and significance. In each regression, both of the coefficients on input trade costs are statistically significant at a $1 \%$ level. For the coefficients on final-good trade costs, both of them are statistically significant at a $1 \%$ level in the regressions for job expansions and the net intensive margin, but only of them is statistically significant (at a 10\% level) in the regressions for job contractions. In the discussion below we focus on the specifications that include industry-level controls.

For a decline in input trade costs, the results in Table 2 are consistent with Predictions 1 and 2. In the least productive establishment a decline in input trade costs leads to reduced job expansion and increased job contraction $\left(\hat{\beta}_{e}^{\lambda}>0\right.$ and $\left.\hat{\beta}_{c}^{\lambda}<0\right)$, and therefore, the intensive-margin components reinforce each other and cause net job destruction $\left(\hat{\beta}^{\lambda} \equiv \hat{\beta}_{e}^{\lambda}-\hat{\beta}_{c}^{\lambda}>0\right)$. The opposite happens in the most productive establishment $\left(\hat{\beta}_{e}^{\lambda}+2 \hat{\gamma}_{e}^{\lambda}<0, \hat{\beta}_{c}^{\lambda}+2 \hat{\gamma}_{c}^{\lambda}>0\right)$, and hence there is net job creation after a decline in input trade costs $\left(\hat{\beta}^{\lambda}+2 \hat{\gamma}^{\lambda}<0\right)$. For the median establishment (with a relative productivity of 1 ), a decline in input trade costs causes net job destruction at the intensive margin $\left(\hat{\beta}^{\lambda}+\hat{\gamma}^{\lambda}>0\right)$. Note also that the effect of a reduction in input trade costs on the intensive margin of employment has a larger impact on the job-expansion rate than on the job-contraction rate: 
the input-trade-cost coefficients in the regression of job expansions (for both the change and the interaction) are about $65 \%$ of the magnitude of the input-trade-cost coefficients in the net intensive margin regression.

We obtain similar implications for a reduction in final-good trade costs: support for Predictions 1 and 2 and the impact being larger for job expansions. More importantly, the final-good tradecost coefficients are smaller in magnitude than the input-trade-cost coefficients. Consider the net-intensive-margin regression in column (6) of Table 2 . Note that $\hat{\beta}^{\lambda}=1.935$ is 2.3 times larger than $\hat{\beta}^{\tau}=0.842$, and $\hat{\gamma}^{\lambda}=-1.833$ is about 2.6 times $\hat{\gamma}^{\tau}=-0.712$. These results indicate that a reduction in input trade costs has a stronger impact on establishment-level employment than a reduction in final-good trade costs.

To look further at this issue, Figure 11 presents a detailed comparison of the effects of input and final-good trade costs on the intensive margin of job flows for each level of (establishment) relative productivity-Figures 11a, 11b, and 11c are based, respectively, on the regressions in columns (2), (4), and (6) in Table 2. Relative productivity, $\Phi \in(0,2)$, is on the $x$-axis in every sub-figure. For job expansions (Figure 11a), the panel on the left presents $\hat{\beta}_{e}^{\lambda}+\hat{\gamma}_{e}^{\lambda} \Phi$ (solid line) and $\hat{\beta}_{e}^{\tau}+\hat{\gamma}_{e}^{\tau} \Phi$ (dashed line) with $90 \%$ confidence bands, and the panel on the right shows their difference, $\hat{\beta}_{e}^{\lambda}+\hat{\gamma}_{e}^{\lambda} \Phi-\left(\hat{\beta}_{e}^{\tau}+\hat{\gamma}_{e}^{\tau} \Phi\right)$, also with $90 \%$ confidence bands. Figures $11 \mathrm{~b}$ and 11c show similar plots for job contractions and the net intensive margin.

For reductions in both types of trade costs, establishments close to the median productivity show employment responses that are very close to zero, but the responses become quantitatively significant and start to diverge from each other as we move away from the center. For the least productive establishment ( $\Phi \rightarrow 0$ from the right), the input-trade-cost effect is 1.9 times as large as the final-good trade-cost effect for job expansions, 3.7 times as large for contractions, and 2.3 times as large for the net intensive margin. For the most productive establishment $(\Phi \rightarrow 2$ from the left), the input-trade-cost effect is 3 times as large as the final-good trade-cost effect for expansions, 2.8 times as large for contractions, and 3 times as large for the net intensive margin. Although the confidence bands for the semi-elasticities of input and final-good trade costs overlap, their difference for the net intensive margin effects is statistically significant for the most productive establishments. Overall, Figure 11 shows a clear pattern pointing towards the greater importance of input trade costs.

In section 6 we perform four types of robustness checks for our intensive-margin results. First, we re-estimate models (17), (18), and (19) using one-year differences. Second, we perform an instrumental variables (IV) estimation to verify if our results are sensitive to the exogeneity assumption made on trade cost changes. Third, we re-estimate the models using relative average employment 

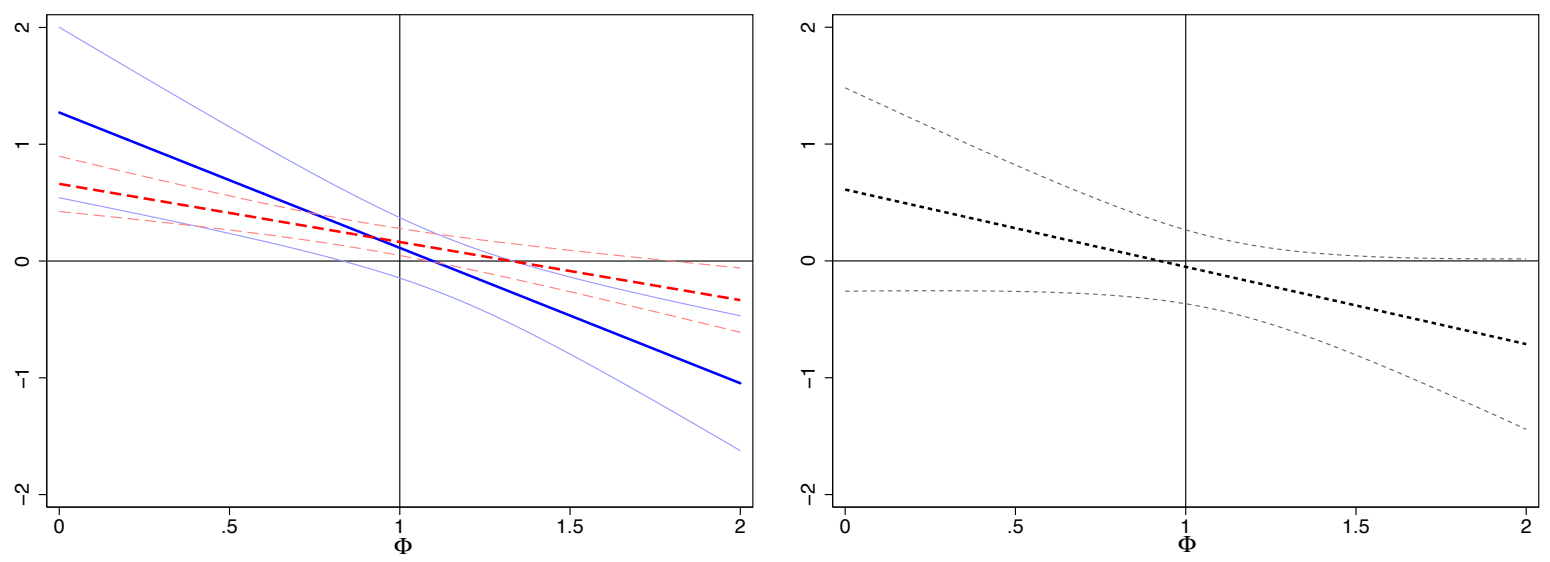

(a) Job expansions: $\hat{\beta}_{e}^{\lambda}+\hat{\gamma}_{e}^{\lambda} \Phi$ (solid), $\hat{\beta}_{e}^{\tau}+\hat{\gamma}_{e}^{\tau} \Phi$ (dashed), and their difference (dotted)
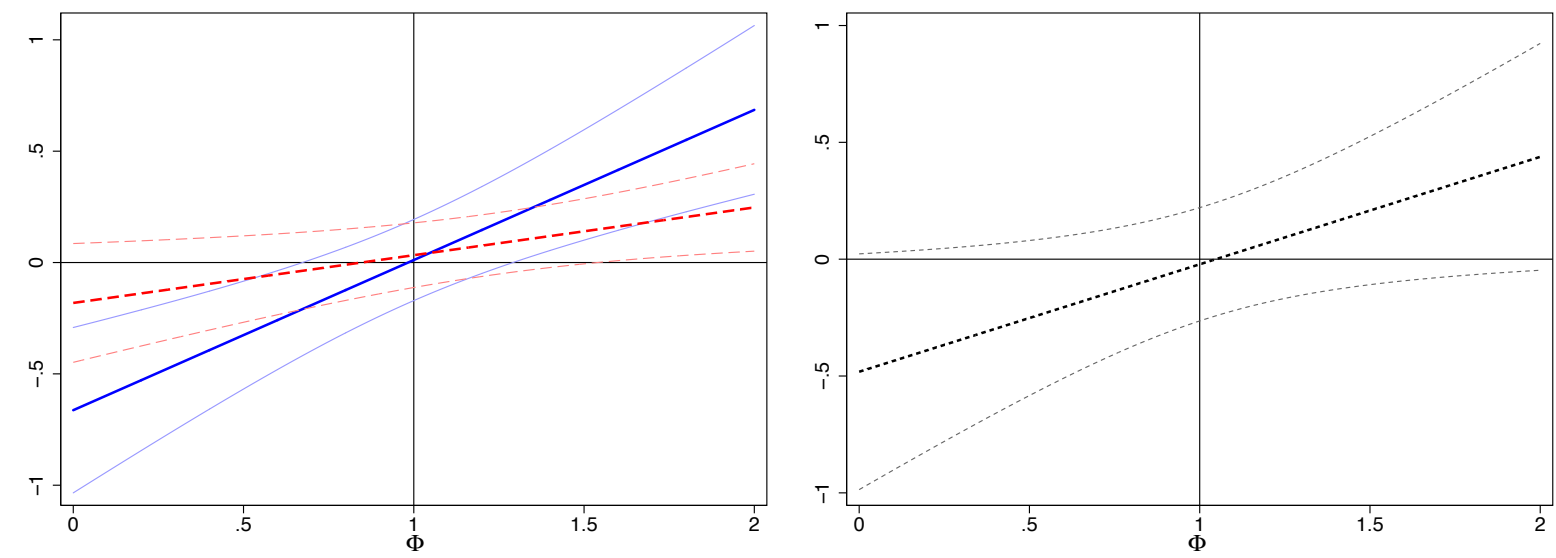

(b) Job contractions: $\hat{\beta}_{c}^{\lambda}+\hat{\gamma}_{c}^{\lambda} \Phi$ (solid), $\hat{\beta}_{c}^{\tau}+\hat{\gamma}_{c}^{\tau} \Phi$ (dashed), and their difference (dotted)
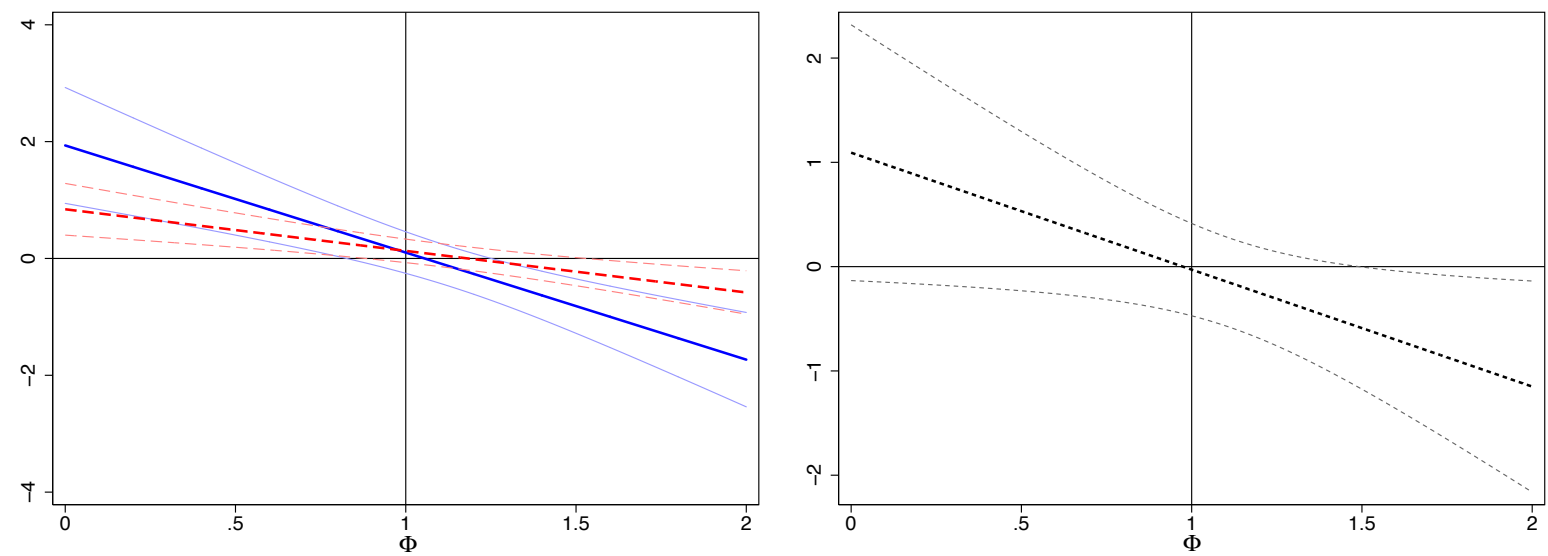

(c) Net intensive margin: $\hat{\beta}^{\lambda}+\hat{\gamma}^{\lambda} \Phi$ (solid), $\hat{\beta}^{\tau}+\hat{\gamma}^{\tau} \Phi$ (dashed), and their difference (dotted)

Figure 11: Semi-elasticities with respect to input and final-good trade costs, their difference, and $90 \%$ confidence bands

instead of relative average sales as the measure of relative productivity - the purpose of this check is to verify the consistency of the size variable used to construct our productivity ranking. And fourth, with the purpose of using all available data (but at the cost of introducing serial correlation), 
we estimate the models using three-year overlapping windows.

\section{Death-Likelihood Estimation}

Prediction 3 states that a decline in input or final-good trade costs should be associated with an increase in the death probability of low-productivity firms. To test this prediction we start from the following binary regression model:

$$
d_{i j t}=\beta_{d}^{\lambda} \lambda_{j t-1}+\beta_{d}^{\tau} \tau_{j t-1}+\gamma_{d}^{\lambda} \lambda_{j t-1} \Phi_{i j}+\gamma_{d}^{\tau} \tau_{j t-1} \Phi_{i j}+\theta_{i}^{d}+\varsigma_{s t}^{d}+\varpi_{d} \Psi_{i t}+\kappa_{d} \Upsilon_{j t-1}+\varepsilon_{i j t}^{d},
$$

where $d_{i j t}$ takes the value of 1 if establishment $i$ from industry $j$ died between $t-1$ and $t$ (and zero otherwise). By definition, the binary dependent variable does not follow any establishment trend and hence, the model in (21) does not include the trend term considered in model (16). Taking the first difference of equation (21), the econometric model to estimate is

$$
\dot{d}_{i j t}=\beta_{d}^{\lambda} \dot{\lambda}_{j t-1}+\beta_{d}^{\tau} \dot{\tau}_{j t-1}+\gamma_{d}^{\lambda} \dot{\lambda}_{j t-1} \Phi_{i j}+\gamma_{d}^{\tau} \dot{\tau}_{j t-1} \Phi_{i j}+\dot{\zeta}_{s t}^{d}+\varpi_{d} \dot{\Psi}_{i t}+\kappa_{d} \dot{\Upsilon}_{j t-1}+\dot{\varepsilon}_{i j t}^{d},
$$

where a "dot" denotes the variable's first difference, $\dot{d}_{i j t}=d_{i j t}$, and the explanatory variables are defined as in section 4.2. ${ }^{23}$ We estimate (22) using a linear probability model, but we also provide results for probit and logit regression models.

The effect of input trade costs on the death probability of an establishment with relative productivity $\Phi$ is given by $\beta_{d}^{\lambda}+\gamma_{d}^{\lambda} \Phi$, for $\Phi \in(0,2)$. In the linear probability model these parameters directly represent death-probability changes: a one percentage point increase in the input trade cost (e.g. from 0.05 to 0.06 ) changes the death probability of a firm with relative productivity $\Phi$ in $\beta_{d}^{\lambda}+\gamma_{d}^{\lambda} \Phi$ percent. The same is true for the final-good trade-cost effect on the establishment's death probability, $\beta_{d}^{\tau}+\gamma_{d}^{\tau} \Phi$.

As in the intensive-margin estimation, we first estimate (22) assuming that heterogeneity does not matter for the effects of input and final-good trade costs on establishments' death likelihood; that is, we impose the restriction $\gamma_{d}^{\lambda}=\gamma_{d}^{\tau}=0$. Table 3 presents the results for the restricted estimation. These results suggest that input trade costs do not explain death likelihood, but they suggest the opposite for final-good trade costs. Note that in every regression the coefficient for the change in final-good trade costs is negative and statistically significant at a $1 \%$ level, so that a decline in final-good trade costs implies an increase in the death likelihood of all firms. However, if heterogeneity matters, the results in Table 3 are subject to omitted variable bias.

\footnotetext{
${ }^{23}$ Given that an establishment disappears from our dataset after it dies, it must be the case that $\dot{d}_{i j t}=d_{i j t}-$ $d_{i j t-1}=\mathbb{1}\left\{d_{i j t}=1\right\}$, where $\mathbb{1}\left\{d_{i j t}=1\right\}$ is an indicator function taking the value of 1 if $d_{i j t}=1$ and zero otherwise. It follows that $\dot{d}_{i j t}=d_{i j t}$.
} 
Table 3: Death-Likelihood Estimation without Productivity Interactions

\begin{tabular}{|c|c|c|c|c|c|c|}
\hline \multicolumn{7}{|c|}{ Dependent variable: death indicator $(=1$ if died at time $t)$} \\
\hline \multirow[b]{2}{*}{ Regressor (at $t-1$ ) } & \multicolumn{2}{|c|}{ Linear } & \multicolumn{2}{|c|}{ Probit } & \multicolumn{2}{|c|}{ Logit } \\
\hline & $(1)$ & $(2)$ & $(3)$ & $(4)$ & $(5)$ & $(6)$ \\
\hline$\triangle($ Input trade cost $)$ & $\begin{array}{c}0.113 \\
(0.177)\end{array}$ & $\begin{array}{c}0.106 \\
(0.177)\end{array}$ & $\begin{array}{c}0.424 \\
(0.667)\end{array}$ & $\begin{array}{c}0.379 \\
(0.670)\end{array}$ & $\begin{array}{c}0.779 \\
(1.177)\end{array}$ & $\begin{array}{c}0.686 \\
(1.180)\end{array}$ \\
\hline$\triangle($ Final-good trade cost $)$ & $\begin{array}{c}-0.314^{* * *} \\
(0.076)\end{array}$ & $\begin{array}{c}-0.322^{* * *} \\
(0.072)\end{array}$ & $\begin{array}{c}-1.196^{* * *} \\
(0.308)\end{array}$ & $\begin{array}{c}-1.224^{* * *} \\
(0.290)\end{array}$ & $\begin{array}{c}-2.173^{* * *} \\
(0.555)\end{array}$ & $\begin{array}{c}-2.216^{* * *} \\
(0.526)\end{array}$ \\
\hline controls & No & Yes & No & Yes & No & Yes \\
\hline Observations & 276,367 & 276,367 & 276,367 & 276,367 & 276,367 & 276,367 \\
\hline
\end{tabular}

Notes: All regressions include industry-time fixed effects (defined at the two-digit SIC level), and the establishment's log age. Industry-level controls (at four-digit SIC level) are the lagged log difference of: the price and value of shipments, the price of materials, total factor productivity, and the industry's employment level. Robust standard errors (in parentheses) clustered at the four-digit SIC industry level. The coefficients are statistically significant at the $* 10 \%, * * 5 \%$, or $* * * 1 \%$ level.

To check if heterogeneity matters, Table 4 shows the unrestricted estimation. The results are very different from those in Table 3. All the input and final-good trade cost coefficients (the change and the productivity interaction) in all the specifications are statistically significant at a $1 \%$ level. All the regressions also tell the same story - they have the same signs and relative magnitudes — and hence, for ease of interpretation, we focus our discussion on the linear probability model's results with industry-level controls (column (2) in Table 4).

For a reduction in input trade costs, the results are consistent with Prediction 3: a decline in input trade costs leads to an increase in the death likelihood of the least productive establishment $\left(\hat{\beta}_{d}^{\lambda}<0\right)$. Since $\hat{\gamma}_{d}^{\lambda}>0$, the adverse effect on death likelihood becomes smaller as relative productivity increases. For the median firm $(\Phi=1)$ we obtain $\hat{\beta}_{d}^{\lambda}+\hat{\gamma}_{d}^{\lambda}>0$, so that this firm's death likelihood declines after a reduction in input trade costs. It follows that the most productive establishment's death likelihood also decreases after a decline in input trade costs $\left(\hat{\beta}_{d}^{\lambda}+2 \hat{\gamma}_{d}^{\lambda}>0\right)$.

We also obtain support for Prediction 3 for a reduction in final-good trade costs. We obtain $\hat{\beta}_{d}^{\tau}<0$ and $\hat{\gamma}_{d}^{\tau}>0$ so that there in an increase in the death likelihood of the least productive establishment after a decline in final-good trade costs, with the effect becoming smaller as relative productivity increases. An important difference from the effect of input trade costs is that after a decline in final-good trade costs, we do not observe a decrease in death likelihood for any type of firm: $\hat{\beta}_{d}^{\tau}+2 \hat{\gamma}_{d}^{\tau}<0$ for every $\Phi \in[0,2]$ (even for the most productive firm, note that $\hat{\beta}_{d}^{\tau}+2 \hat{\gamma}_{d}^{\tau}=-0.008$ ). Additionally, and similar to the intensive margin estimation, the input-trade-cost coefficients are larger in magnitude than the final-good trade-cost coefficients, $\left|\hat{\beta}_{d}^{\lambda}\right|>\left|\hat{\beta}_{d}^{\tau}\right|$ and $\hat{\gamma}_{d}^{\lambda}>\hat{\gamma}_{d}^{\tau}$, indicating the greater importance of input trade costs.

Using the results of regression (2) in Table 4, Figure 12 shows the estimated death-probability 
Table 4: Death-Likelihood Estimation and Productivity

\begin{tabular}{lcccccc}
\hline \hline \multirow{2}{*}{ Dependent variable: death indicator $(=1$ if died at time $t)$} & & & \\
& \multicolumn{2}{c}{ Linear } & \multicolumn{2}{c}{ Probit } & \multicolumn{2}{c}{ Logit } \\
\cline { 2 - 7 } Regressor (at $\boldsymbol{t}-\mathbf{1})$ & $(1)$ & $(2)$ & $(3)$ & $(4)$ & $(5)$ & $(6)$ \\
\hline \multirow{3}{*}{$\triangle($ Input trade cost) } & $-0.998^{* *}$ & $-1.010^{* * *}$ & $-4.389^{* * *}$ & $-4.453^{* * *}$ & $-7.735^{* * *}$ & $-7.872^{* * *}$ \\
& $(0.392)$ & $(0.390)$ & $(1.457)$ & $(1.455)$ & $(2.466)$ & $(2.463)$ \\
$\times($ Relative Productivity) & $1.057^{* * *}$ & $1.062^{* * *}$ & $4.763^{* * *}$ & $4.781^{* * *}$ & $8.619^{* * *}$ & $8.662^{* * *}$ \\
& $(0.348)$ & $(0.348)$ & $(1.384)$ & $(1.383)$ & $(2.428)$ & $(2.427)$ \\
$\triangle($ Final-good trade cost) & $-0.648^{* * *}$ & $-0.652^{* * *}$ & $-2.311^{* * *}$ & $-2.328^{* * *}$ & $-4.097^{* * *}$ & $-4.130^{* * *}$ \\
& $(0.143)$ & $(0.139)$ & $(0.523)$ & $(0.510)$ & $(0.904)$ & $(0.885)$ \\
$\times($ Relative Productivity) & $0.326^{* * *}$ & $0.322^{* * *}$ & $1.110^{* * *}$ & $1.101^{* * *}$ & $1.939^{* * *}$ & $1.932^{* * *}$ \\
& $(0.104)$ & $(0.104)$ & $(0.373)$ & $(0.374)$ & $(0.646)$ & $(0.651)$ \\
Industry-level controls & No & Yes & No & Yes & No & Yes \\
Observations & 276,367 & 276,367 & 276,367 & 276,367 & 276,367 & 276,367 \\
\hline \hline
\end{tabular}

Notes: All regressions include industry-time fixed effects (defined at the two-digit SIC level), and the establishment's log age. Industry-level controls (at four-digit SIC level) are the lagged log difference of: the price and value of shipments, the price of materials, total factor productivity, and the industry's employment level. Robust standard errors (in parentheses) clustered at the four-digit SIC industry level. The coefficients are statistically significant at the $* 10 \%,{ }^{* *} 5 \%$, or $* * * 1 \%$ level.

responses, $\hat{\beta}_{d}^{\lambda}+\hat{\gamma}_{d}^{\lambda} \Phi$ and $\hat{\beta}_{d}^{\tau}+\hat{\gamma}_{d}^{\tau} \Phi$, along with their difference and $90 \%$ confidence bands. A reduction in input trade costs increases the death probability for about half of the establishments (the least-productive half), and decreases it for the other half: a one percentage point decline in the input trade cost increases the death probability by about $1 \%$ for the least-productive establishment $(\Phi \rightarrow 0)$, has no change for the establishment in the median $(\Phi=1)$, and decreases it by about $1.1 \%$ for the most productive establishment $(\Phi \rightarrow 2)$. On the other hand, a one percentage point decline in final-good trade costs increases the death probability of the least-productive establishment by about $0.65 \%$ and has no effect on the most productive one. Note from Figure $12 \mathrm{~b}$ that the difference between input and final-good trade-cost responses is statistically significant for more than half of the establishments.

Our results for the effect of final-good trade costs on the death probability of establishments are similar to the results of Bernard, Jensen, and Schott (2006b), and hence provide support for the theoretical channels identified in the heterogeneous-firm models of trade in final goods of Bernard, Eaton, Jensen, and Kortum (2003) and Melitz (2003). Nevertheless, our results also show that we should not ignore the effects of input trade costs, which are larger in magnitude than the effects of final-good trade costs to explain establishment-level employment and death-likelihood outcomes.

As we should expect, the effects of trade costs on death likelihood translate into firm-level predictions at the extensive margin of employment. For a reduction in input trade costs, (the least productive) half of the establishments are more likely to destroy jobs due to death, while this 


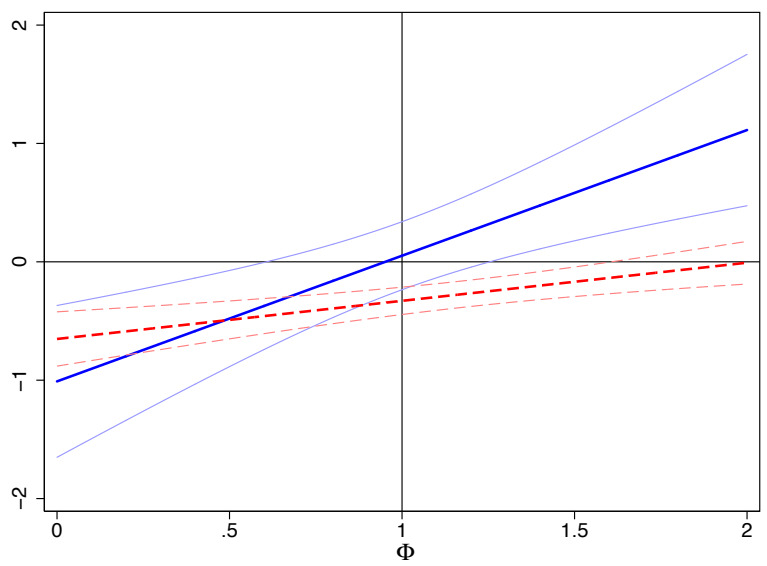

(a) $\hat{\beta}_{d}^{\lambda}+\hat{\gamma}_{d}^{\lambda} \Phi\left(\right.$ solid) and $\hat{\beta}_{d}^{\tau}+\hat{\gamma}_{d}^{\tau} \Phi($ dashed $)$

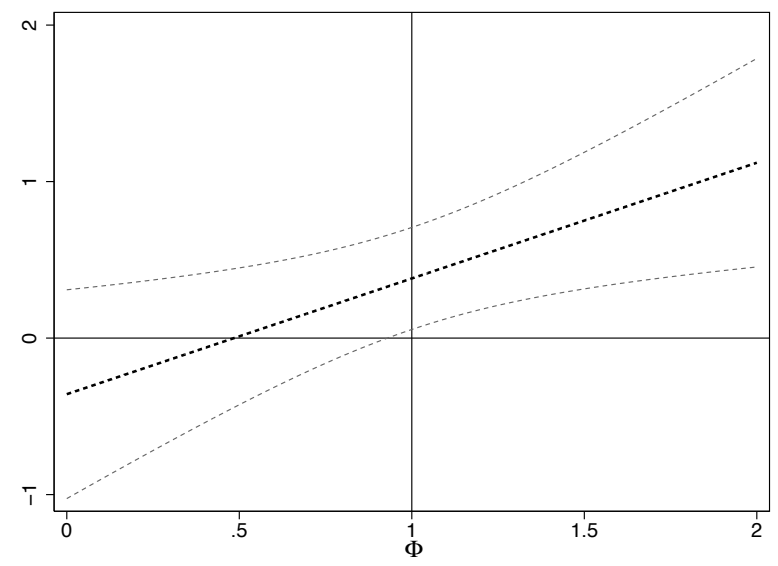

(b) Difference

Figure 12: Death-likelihood responses to input and final-good trade costs with $90 \%$ confidence bands

likelihood declines for the other half. On the other hand, a reduction in final-good trade costs implies a higher likelihood of destroying jobs by death for all the establishments, but the effect is negligible for the most productive firms.

\section{Robustness}

In this section, we perform four robustness checks for the econometric specifications in equations (17), (18), (19), and (22). We contrast the results in this section against the results presented in Tables 2 and 4 in the paper. We focus our comparison on regressions with industry-level controls, and on the linear model for the death-likelihood estimation-columns (2), (4), and (6) in Table 2, and column (2) in Table 4. Figures 13 and 14 below present a graphical summary of the robustness checks. In addition, section C.2 in the Appendix includes a fifth robustness check that considers splitting our trade cost measures into tariff and freight components.

\subsection{One-Year Differences}

The first robustness check uses one-year changes in all the variables (i.e. annual first differences), instead of three-year changes. The benchmark regressions are based on three-year differences to account for the fact that the effects of a reduction in trade costs are better captured over longer periods of time - the effects of lower trade barriers take time to be reflected into firms' production and employment decisions - and to take care of the apparent stickiness of the NETS data discussed in section 3.1.1. Nevertheless, this check allows us to shed light on the temporal dimension of the effects of input and final-good trade costs; that is, we can analyze whether or not establishments 


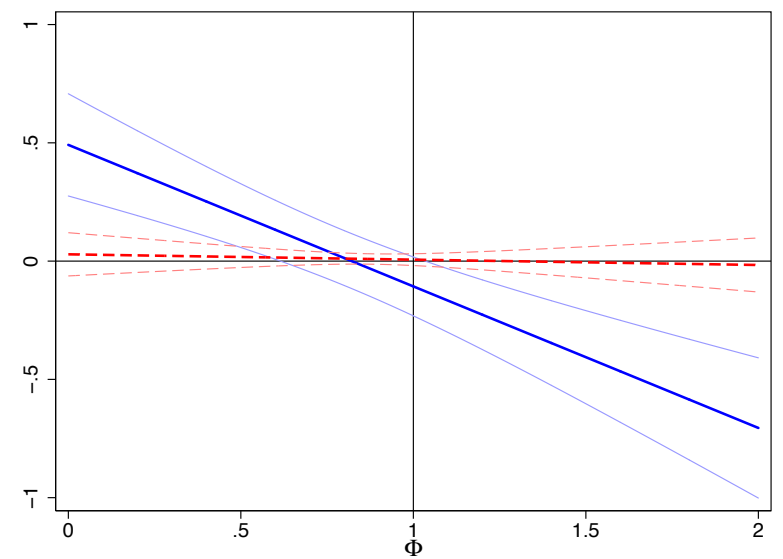

(a) First check: Annual changes

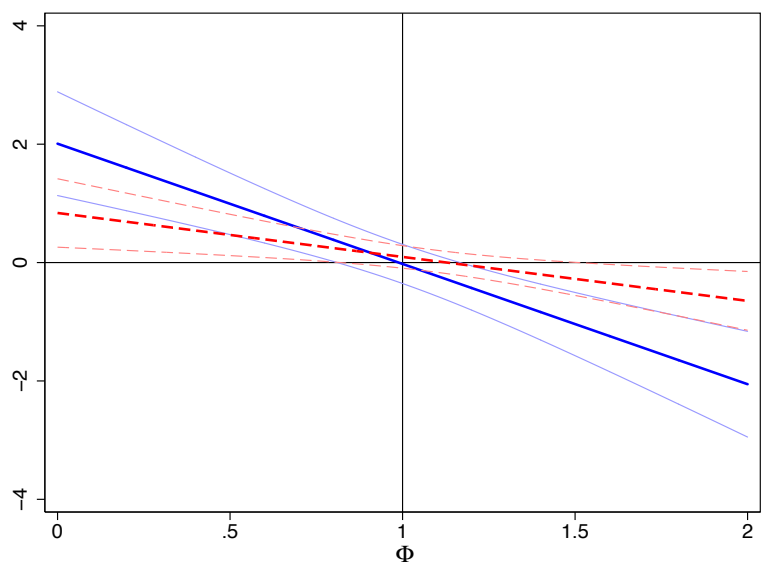

(c) Third check: Average employment

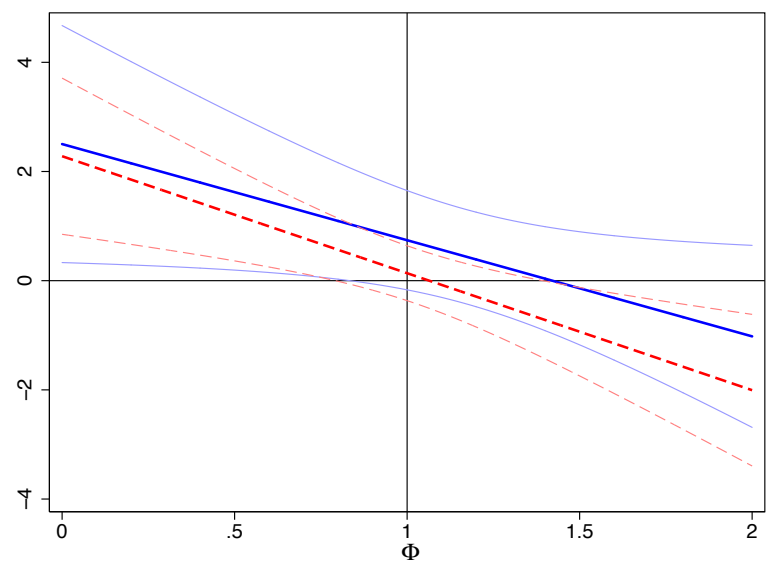

(b) Second check: Instrumental variables

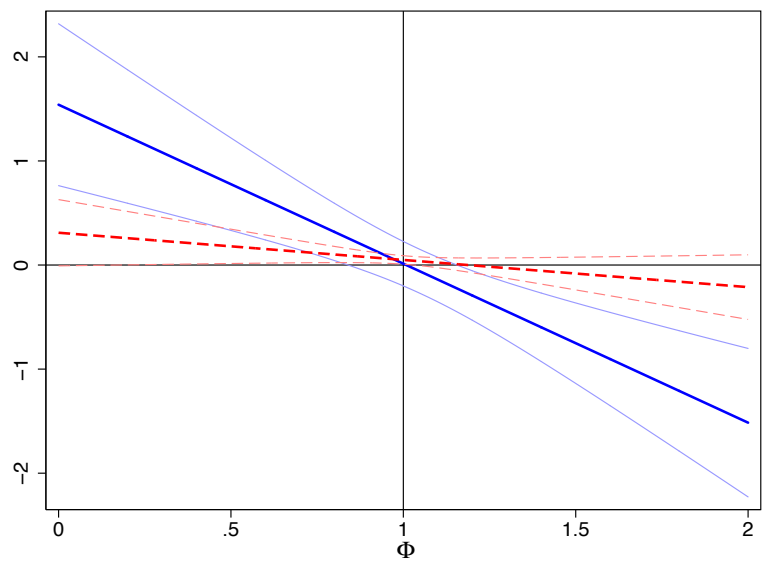

(d) Fourth check: Overlapping periods

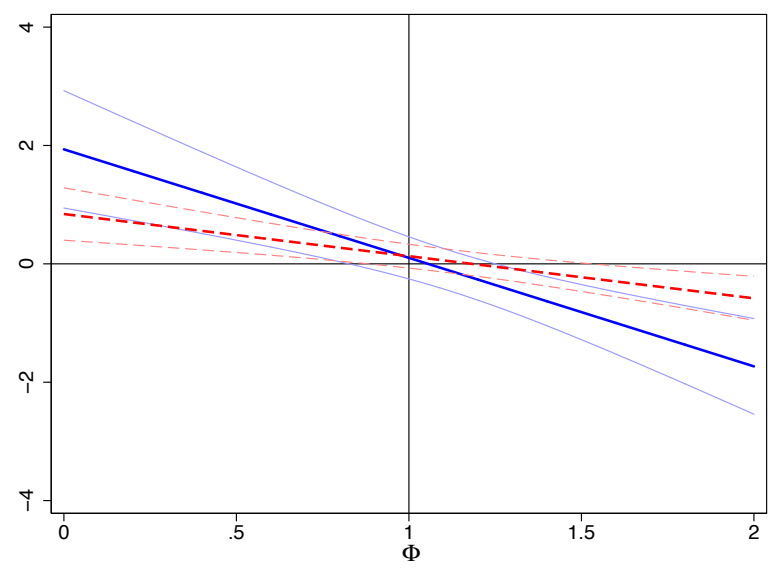

(e) Benchmark

Figure 13: Net-intensive-margin semi-elasticities with respect to input trade costs (solid) and finalgood trade costs (dashed), with $90 \%$ confidence bands 


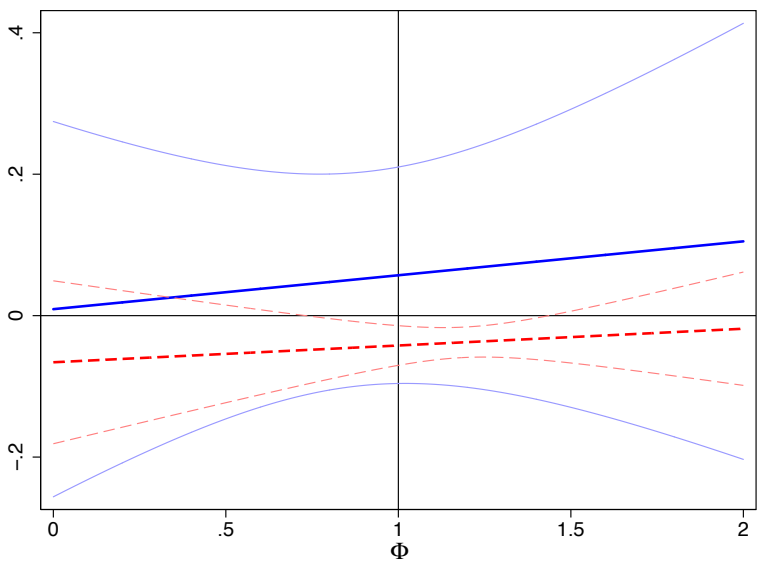

(a) First check: Annual changes

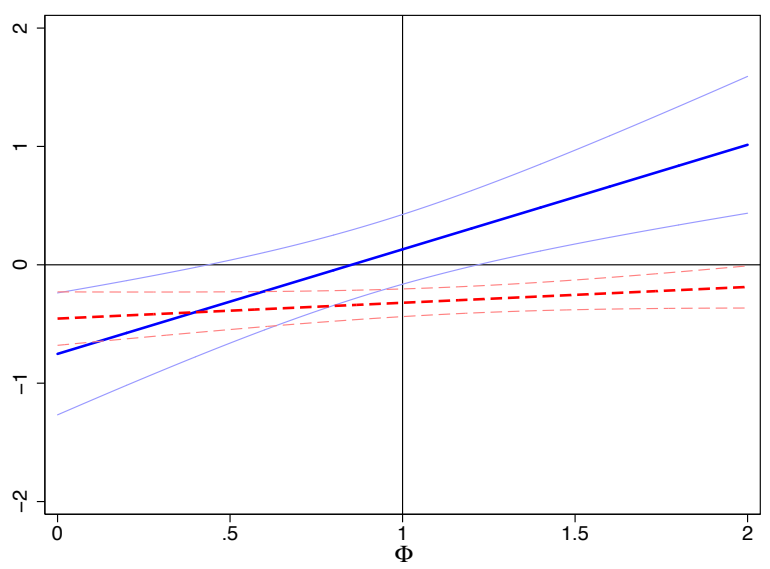

(c) Third check: Average employment

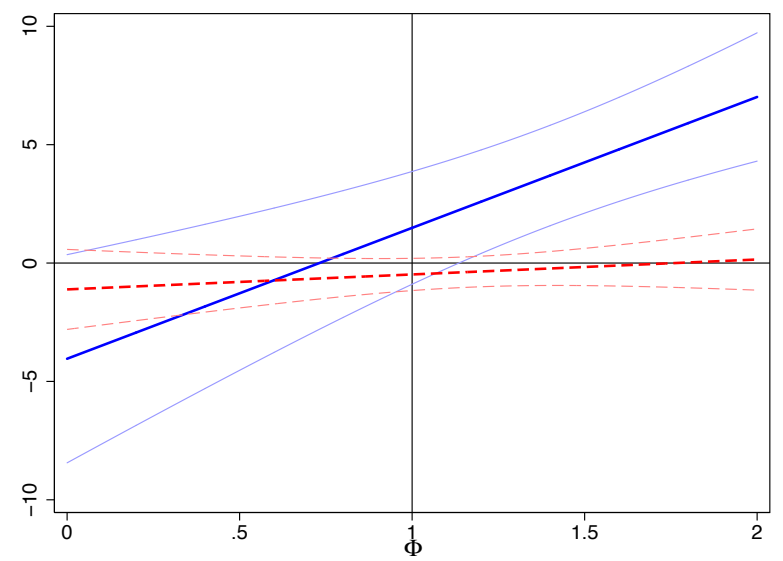

(b) Second check: Instrumental variables

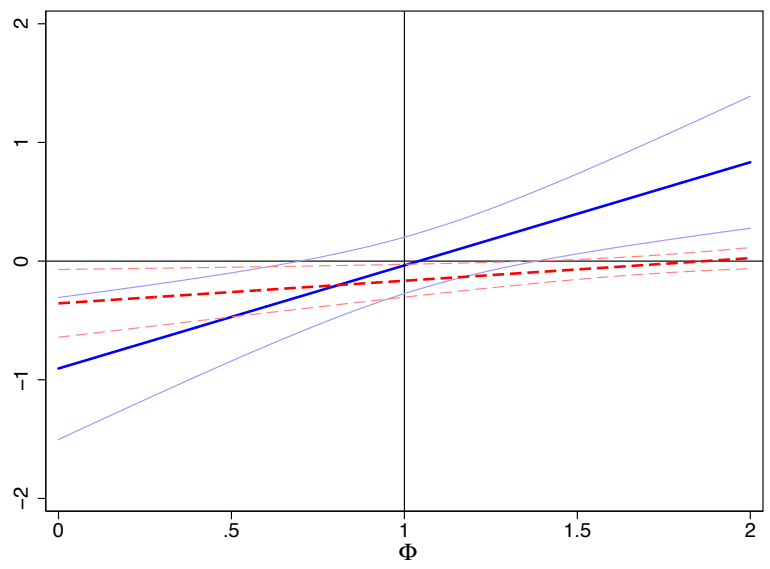

(d) Fourth check: Overlapping periods

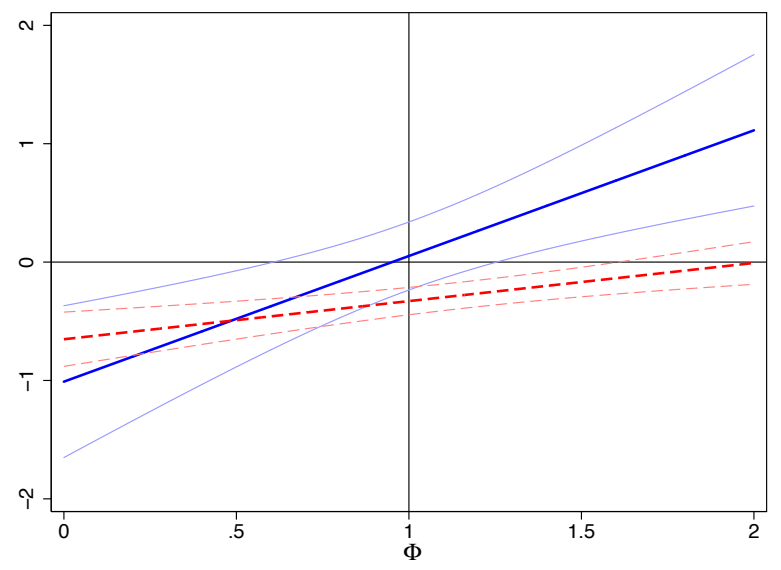

(e) Benchmark

Figure 14: The effects of input trade costs (solid) and final-good trade costs (dashed) in the linear death-likelihood regression, with $90 \%$ confidence bands 
Table 5: First Robustness Check - Annual Changes

\begin{tabular}{|c|c|c|c|c|}
\hline \multicolumn{5}{|c|}{ Dependent variable (at time $t$ ) indicated in columns } \\
\hline Regressor (at $t-1$ ) & $\begin{array}{c}\text { Job } \\
\text { expansions } \\
(e)\end{array}$ & $\begin{array}{c}\text { Job } \\
\text { contractions } \\
(c) \\
\end{array}$ & $\begin{array}{c}\text { Net intensive } \\
\text { margin } \\
(\dot{E} \equiv e-c)\end{array}$ & $\begin{array}{c}\text { Death } \\
\text { indicator } \\
(d)\end{array}$ \\
\hline$\triangle($ Input trade cost $)$ & $\begin{array}{c}0.394^{* * *} \\
(0.088)\end{array}$ & $\begin{array}{l}-0.097 \\
(0.079)\end{array}$ & $\begin{array}{c}0.491^{* * *} \\
(0.131)\end{array}$ & $\begin{array}{c}0.009 \\
(0.161)\end{array}$ \\
\hline$\times$ (Relative Productivity) & $\begin{array}{c}-0.440^{* * *} \\
(0.085)\end{array}$ & $\begin{array}{l}0.158^{*} \\
(0.086)\end{array}$ & $\begin{array}{c}-0.598^{* * *} \\
(0.138)\end{array}$ & $\begin{array}{c}0.048 \\
(0.148)\end{array}$ \\
\hline$\triangle($ Final-good trade cost $)$ & $\begin{array}{c}0.025 \\
(0.045)\end{array}$ & $\begin{array}{l}-0.004 \\
(0.014)\end{array}$ & $\begin{array}{c}0.029 \\
(0.056)\end{array}$ & $\begin{array}{l}-0.066 \\
(0.070)\end{array}$ \\
\hline$\times$ (Relative Productivity) & $\begin{array}{l}-0.021 \\
(0.052)\end{array}$ & $\begin{array}{c}0.001 \\
(0.014)\end{array}$ & $\begin{array}{l}-0.023 \\
(0.061)\end{array}$ & $\begin{array}{c}0.024 \\
(0.058)\end{array}$ \\
\hline Industry-level controls & Yes & Yes & Yes & Yes \\
\hline Observations & 775,637 & 775,637 & 775,637 & 839,863 \\
\hline Establishments & 127,467 & 127,467 & 127,467 & \\
\hline
\end{tabular}

Notes: All regressions include industry-time fixed effects (defined at the two-digit SIC level), and the establishment's log age. The first three columns include establishment-level fixed effects. The fourth column shows the linear probability model. Industry-level controls (at four-digit SIC level) are the lagged $\log$ difference of: the price and value of shipments, the price of materials, total factor productivity, and the industry's employment level. Robust standard errors (in parentheses) clustered at the four-digit SIC industry level. The coefficients are statistically significant at the $* 10 \%, * * 5 \%$, or $* * * 1 \%$ level.

respond faster to a reduction in input trade costs than to a reduction in final-good trade costs.

Table 5 shows the estimation results with one-year differences. The first three columns refer to the intensive-margin estimation and the last column refers to the death-likelihood estimation. Let us compare first the intensive-margin results. The estimated coefficients of input trade costs have the same signs as in Table 2 and continue to be statistically significant at the $1 \%$ level for expansions and the net intensive margin (for job contractions, only the interaction term is significant at a $10 \%$ level) - as in the benchmark results, a reduction in input trade costs affects job flows at the intensive margin mostly through the impact on the job-expansion rate. Also, the magnitudes of the input-trade-cost coefficients for the net intensive margin regression are between 1/3 and 1/4 of the magnitudes of the respective benchmark (three-year difference) coefficients. This indicates that a decline in input trade costs starts having an impact on the intensive margin of employment without much lag.

On the other hand, though the final-good trade-cost coefficients for the intensive margin regressions have the same signs as in the benchmark results, they are not statistically significant and their magnitudes are negligible. Therefore, at one-year horizons a reduction in final-good trade costs seems to be irrelevant for establishment-level expansion and contraction decisions. The negligible response observed for a reduction in final-good trade costs may also be due to the NETS data 
stickiness, but even if this was the case, the intensive-margin results in Table 5 show that input trade costs are far more relevant than final-good trade costs at shorter horizons.

Figure 13a shows the net-intensive-margin semi-elasticities for this robustness check. In comparison to Figure 13e, which shows again benchmark semi-elasticities, note that with the exception of the negligible relevance of final-good trade costs for one-year horizons, the rest of our intensivemargin conclusions hold.

For the death-likelihood estimation, both input and final-good trade costs are quantitatively and statistically insignificant at one-year horizons. This contrasts with the very strong and significant results we obtained for the three-year regressions (see the difference between Figures 14a and 14e). Hence, either all establishments' exit decisions after a reduction in trade costs are only realized at longer term horizons (the exit decision of an establishment is far more serious than an expansion or contraction decision), or NETS has important problems in tracking establishments' deaths the year they occur (see Neumark, Wall, and Zhang, 2011), or (more likely) a combination of both.

\subsection{Instrumental Variables}

An important consideration is the possibility that industries' lobbying groups might look for trade protection when there are employment losses, making tariff rates endogenous. ${ }^{24}$ Since it is unlikely that individual establishments affect country-wide trade policy, we do not consider the problem of endogenous protection in our benchmark establishment-level estimation. Supporting this view, Trefler (2004) uses plant-level data from Canada, and finds that the endogeneity of tariffs is strongly rejected in his plant-level specifications for employment growth and labor productivity. As he puts it, "this likely reflects the fact that tariffs, even if endogenous to the industry, are exogenous to the plant."

In spite of this evidence and for completeness purposes, this robustness check re-estimates equations (17), (18), (19), and (22) using an instrumental variables (IV) approach. The estimation relies on the use of lagged differences in trade costs as instruments. ${ }^{25}$ Table 6 presents the results of the IV estimation.

Before looking at the trade-cost coefficients, let us briefly describe the first-stage regressions

\footnotetext{
${ }^{24}$ There is a large literature on endogenous trade protection. Theoretically, the model of "protection for sale" of Grossman and Helpman (1994) provides a framework to analyze this issue. Using U.S. data, Goldberg and Maggi (1999) find support for the Grossman-Helpman model. Also for the U.S., Trefler (1993) finds that estimates for the effect of trade protection on imports are much larger once endogeneity is taken care of.

${ }^{25}$ The use of lagged endogenous variables as instruments is a common practice in dynamic panel data models (see, for example, the estimator proposed by Arellano and Bond (1991) and all its relatives). In the context of trade costs, our approach is equivalent to the approach used by Estevadeordal, Freund, and Ornelas (2008) to instrument for preferential tariffs in one of their two specifications. Goldberg and Pavcnik (2005) propose a related approach to instrument for changes in tariffs in a panel-data setting. In their analysis on the effect of trade costs on wage premiums in Colombia, they create instruments for tariff changes based on the interaction of the initial level of tariffs with coffee prices and exchange rates.
} 
Table 6: Second Robustness Check — Instrumental Variables

\begin{tabular}{|c|c|c|c|c|}
\hline \multicolumn{5}{|c|}{ Dependent variable (at time $t$ ) indicated in columns } \\
\hline Regressor (at $t-1)$ & $\begin{array}{c}\text { Job } \\
\text { expansions } \\
(e)\end{array}$ & $\begin{array}{c}\text { Job } \\
\text { contractions } \\
(c) \\
\end{array}$ & $\begin{array}{c}\text { Net intensive } \\
\text { margin } \\
(\dot{E} \equiv e-c)\end{array}$ & $\begin{array}{c}\text { Death } \\
\text { indicator } \\
(d)\end{array}$ \\
\hline$\triangle($ Input trade cost $)$ & $\begin{array}{l}1.514^{*} \\
(0.908)\end{array}$ & $\begin{array}{l}-0.989^{*} \\
(0.585)\end{array}$ & $\begin{array}{l}2.503^{*} \\
(1.320)\end{array}$ & $\begin{array}{l}-4.042 \\
(2.673)\end{array}$ \\
\hline$\times$ (Relative Productivity) & $\begin{array}{l}-0.985 \\
(0.754)\end{array}$ & $\begin{array}{l}0.776^{*} \\
(0.460)\end{array}$ & $\begin{array}{c}-1.761^{*} \\
(1.039)\end{array}$ & $\begin{array}{c}5.528^{* * *} \\
(1.683)\end{array}$ \\
\hline$\triangle($ Final-good trade cost $)$ & $\begin{array}{l}1.581^{* *} \\
(0.615)\end{array}$ & $\begin{array}{l}-0.699 \\
(0.483)\end{array}$ & $\begin{array}{c}2.280^{* * *} \\
(0.870)\end{array}$ & $\begin{array}{l}-1.113 \\
(1.027)\end{array}$ \\
\hline$\times$ (Relative Productivity) & $\begin{array}{c}-1.374^{* * *} \\
(0.524)\end{array}$ & $\begin{array}{l}0.769^{*} \\
(0.438)\end{array}$ & $\begin{array}{c}-2.143^{* * *} \\
(0.801)\end{array}$ & $\begin{array}{c}0.632 \\
(0.816)\end{array}$ \\
\hline Industry-level controls & Yes & Yes & Yes & Yes \\
\hline Observations & 110,794 & 110,794 & 110,794 & 158,377 \\
\hline Establishments & 40,550 & 40,550 & 40,550 & \\
\hline Hansen's $J$-test $p$-value & 0.63 & 0.29 & 0.72 & 0.16 \\
\hline Hausman's test $p$-value & 0.56 & 0.76 & 0.60 & 0.69 \\
\hline
\end{tabular}

Notes: All regressions include industry-time fixed effects (defined at the two-digit SIC level), and the establishment's log age. The first three columns include establishment-level fixed effects. The fourth column shows the linear probability model. Industry-level controls (at four-digit SIC level) are the lagged $\log$ difference of: the price and value of shipments, the price of materials, total factor productivity, and the industry's employment level. Robust standard errors (in parentheses) clustered at the four-digit SIC industry level. The coefficients are statistically significant at the $* 10 \%, * * 5 \%$, or $* * * 1 \%$ level.

and discuss the relevance and exogeneity of the instruments. We make a distinction between the set of instruments applicable to the intensive margin regressions, and the set of instruments used in the death-likelihood regression. The instruments for trade-cost changes in the intensive-margin regressions are the lagged trade-cost differences (i.e. changes in the previous three periods), their interactions with the relative productivity variable, squares and cross products, the initial tradecost levels (i.e. lagged three periods), and any other exogenous regressor. For the death-likelihood regression we exclude from the former set the lagged trade-cost levels (otherwise we would reject the null hypothesis of exogeneity of the instruments). The first-stage partial $R^{2}$ for the intensivemargin regressions takes values between 0.39 and 0.53 , while the $F$-statistics are in the range between 12 and 44, which are values well above the critical levels to discard that the instruments are weak. However, in the first-stage of the death-likelihood regressions the partial $R^{2}$ takes values between 0.05 and 0.06 and the $F$-statistics are between 1 and 20. Hence, for the death-likelihood regression we cannot discard the possibility of weak instruments. With respect to the instruments' exogeneity, the penultimate row in each column in Table 6 presents the $p$-value from Hansen's $J$-test of overidentifying restrictions. The null hypothesis that the instruments are exogenous cannot be rejected for any of the regressions (the larger the $p$-value, the better). To sum up, our instruments 
are relevant and exogenous for the intensive-margin regressions, but they satisfy only exogeneity in the death-likelihood regression.

For the intensive-margin estimation, note from the first three columns in Table 6 that the input and final-good trade-cost coefficients (for both the change and the interaction) maintain the same signs as in Table 2. However, the statistical significance of the input-trade-cost coefficients is reduced: one of them is not statistically significant and the other five are significant only at a $10 \%$ level. On the other hand, the final-good trade-cost coefficients maintain their statistical significance but also have an important increase in their magnitude. Note that Predictions 1 and 2 continue to hold in the IV intensive-margin estimation. The difference from the benchmark regression is with respect to the type of trade costs that is more relevant. From the net-intensive-margin regression

in Table 6 , note that $\hat{\beta}^{\lambda}>\hat{\beta}^{\tau}$ but $\left|\hat{\gamma}^{\tau}\right|>\left|\hat{\gamma}^{\lambda}\right|$, and therefore, there is not a clear pattern as to which type of trade costs is more important. Figure 13b highlights this point: the lines for input and final-good trade-cost semi-elasticities never cross, and although the point estimates show a slightly higher response for less productive establishments after a decline in input trade costs (a higher job destruction rate at the intensive margin), the response for the most productive establishments is higher for a reduction in final-good trade costs (a higher job creation rate at the intensive margin).

For the death-likelihood estimation, the last column in Table 6 shows the same signs as in Table 4, though now the coefficients are larger in magnitude and only one of them is statistically significant. Note that Figures $14 \mathrm{~b}$ and $14 \mathrm{e}$ tell the same story. Nevertheless, the potential weakinstruments problem for the death-likelihood IV estimation makes this comparison unreliable.

Finally, in the last row of Table 6 we show the $p$-values from the Hausman test. The high $p$-values indicate that in each of our cases, we cannot reject the null hypothesis that trade-cost variables are exogenous. These results are similar to those of Trefler (2004) mentioned above, and therefore, we are confident that our measures for input and final-good trade costs are exogenous to the establishments.

\subsection{Productivity Measure Based on Average Employment}

The third robustness check uses an alternative measure for establishment relative productivity. In the previous regressions, the relative productivity of establishment $i$ in industry $j, \Phi_{i j} \in(0,2)$, is based on the establishment's average-real-sales ranking with respect to its industry peers. Recall that our productivity variable hinges on the assumption of a positive monotonic relationship between size and productivity.

It is common in the literature to use total employment as a firm's proxy for size. This is problematic for our purposes because we study how an establishment's domestic employment responds 
Table 7: Third Robustness Check - Average Employment

\begin{tabular}{|c|c|c|c|c|}
\hline \multicolumn{5}{|c|}{ Dependent variable (at time $t$ ) indicated in columns } \\
\hline Regressor (at $t-1$ ) & $\begin{array}{c}\text { Job } \\
\text { expansions } \\
(e)\end{array}$ & $\begin{array}{c}\text { Job } \\
\text { contractions } \\
(c) \\
\end{array}$ & $\begin{array}{c}\text { Net intensive } \\
\text { margin } \\
(\dot{E} \equiv e-c)\end{array}$ & $\begin{array}{c}\text { Death } \\
\text { indicator } \\
(d)\end{array}$ \\
\hline$\triangle($ Input trade cost $)$ & $\begin{array}{c}1.331^{* * *} \\
(0.414)\end{array}$ & $\begin{array}{c}-0.678^{* * *} \\
(0.206)\end{array}$ & $\begin{array}{c}2.009^{* * *} \\
(0.533)\end{array}$ & $\begin{array}{c}-0.752^{* *} \\
(0.313)\end{array}$ \\
\hline$\times$ (Relative Productivity) & $\begin{array}{c}-1.297^{* * *} \\
(0.381)\end{array}$ & $\begin{array}{c}0.735^{* * *} \\
(0.205)\end{array}$ & $\begin{array}{c}-2.032^{* * *} \\
(0.499)\end{array}$ & $\begin{array}{c}0.883^{* * *} \\
(0.280)\end{array}$ \\
\hline$\triangle($ Final-good trade cost $)$ & $\begin{array}{c}0.588^{* * *} \\
(0.193)\end{array}$ & $\begin{array}{l}-0.251 \\
(0.185)\end{array}$ & $\begin{array}{c}0.838^{* *} \\
(0.351)\end{array}$ & $\begin{array}{c}-0.454^{* * *} \\
(0.137)\end{array}$ \\
\hline$\times$ (Relative Productivity) & $\begin{array}{c}-0.452^{* *} \\
(0.202)\end{array}$ & $\begin{array}{l}0.291^{* *} \\
(0.138)\end{array}$ & $\begin{array}{c}-0.743^{* *} \\
(0.306)\end{array}$ & $\begin{array}{c}0.134 \\
(0.101)\end{array}$ \\
\hline Industry-level controls & Yes & Yes & Yes & Yes \\
\hline Observations & 219,593 & 219,593 & 219,593 & 276,367 \\
\hline Establishments & 88,606 & 88,606 & 88,606 & \\
\hline
\end{tabular}

Notes: All regressions include industry-time fixed effects (defined at the two-digit SIC level), and the establishment's log age. The first three columns include establishment-level fixed effects. The fourth column shows the linear probability model. Industry-level controls (at four-digit SIC level) are the lagged log difference of: the price and value of shipments, the price of materials, total factor productivity, and the industry's employment level. Robust standard errors (in parentheses) clustered at the four-digit SIC industry level. The coefficients are statistically significant at the $* 10 \%, * * 5 \%$, or $* * * 1 \%$ level.

to reductions in trade costs. It may be the case, for example, that after a reduction in input trade costs a very large and productive firm destroys domestic jobs due to offshoring effects; although the firm's total workforce (domestic labor plus foreign labor) may remain constant, using only domestic labor as a proxy for size may lead us to understate the firm's productivity. However, given its frequent use as a measure for firm's size, in this robustness check we re-estimate the econometric models using average domestic employment to construct the productivity measure.

As before, we take into account that firms grow over time and that productivity takes time to be reflected in firm's size. Therefore, we first obtain the average employment of each establishment using all the years it appears in our dataset, then we rank the establishments by average employment in each industry, and lastly we map the ranking into the $(0,2)$ interval.

Table 7 displays the results from using the average-employment productivity measure. The intensive-margin results are very similar - signs, magnitudes, and statistical significance - to those in Table 2. Comparing Figures 13c and 13e, note that they are nearly identical. Therefore, all our intensive-margin conclusions from section 4 hold.

The death-likelihood conclusions from section 5 also hold. The coefficients in the last column of Table 7 are slightly smaller than those in column (2) of Table 4 but, with the exception of the interaction coefficient for final-good trade costs, they retain statistical significance. Note that 
Table 8: Fourth Robustness Check - Overlapping Periods

\begin{tabular}{lcccc}
\hline \hline Dependent variable (at time $t$ ) & $\begin{array}{c}\text { indicated in columns } \\
\text { Job } \\
\text { expansions } \\
\text { Regressor (at } \boldsymbol{t} \text {-1) }\end{array}$ & $\begin{array}{c}\text { Job } \\
\text { contractions } \\
(\boldsymbol{e})\end{array}$ & $\begin{array}{c}\text { Net intensive } \\
\text { margin }\end{array}$ & $\begin{array}{c}(\dot{\boldsymbol{E}} \equiv \boldsymbol{e}-\boldsymbol{c}) \\
\text { Death } \\
\text { indicator } \\
(\boldsymbol{d})\end{array}$ \\
\hline (Input trade cost) & $1.080^{* * *}$ & $-0.460^{* *}$ & $1.540^{* * *}$ & $-0.905^{* *}$ \\
& $(0.356)$ & $(0.188)$ & $(0.473)$ & $(0.364)$ \\
$\times($ Relative Productivity) & $-1.080^{* * *}$ & $0.447^{* * *}$ & $-1.528^{* * *}$ & $0.869^{* * *}$ \\
& $(0.314)$ & $(0.169)$ & $(0.435)$ & $(0.320)$ \\
$\triangle$ (Final-good trade cost) & 0.126 & $-0.185^{* * *}$ & 0.310 & $-0.356^{* *}$ \\
& $(0.138)$ & $(0.063)$ & $(0.194)$ & $(0.174)$ \\
$\times($ Relative Productivity) & -0.095 & $0.166^{* *}$ & -0.261 & $0.191^{*}$ \\
& $(0.128)$ & $(0.066)$ & $(0.190)$ & $(0.097)$ \\
Industry-level controls & Yes & Yes & Yes & Yes \\
Observations & 549,446 & 549,446 & 549,446 & 691,297 \\
Establishments & 93,221 & 93,221 & 93,221 & \\
\hline \hline
\end{tabular}

Notes: All regressions include industry-time fixed effects (defined at the two-digit SIC level), and the establishment's log age. The first three columns include establishment-level fixed effects. The fourth column shows the linear probability model. Industry-level controls (at four-digit SIC level) are the lagged $\log$ difference of: the price and value of shipments, the price of materials, total factor productivity, and the industry's employment level. Robust standard errors (in parentheses) clustered at the four-digit SIC industry level. The coefficients are statistically significant at the $* 10 \%, * * 5 \%$, or $* * * 1 \%$ level.

Figures $14 \mathrm{c}$ and $14 \mathrm{e}$ are very similar.

\subsection{Overlapping Windows}

The fourth robustness check estimates the econometric specifications in (17), (18), (19), and (22) using three-year changes (as in the benchmark case) but with overlapping windows. That is, our panel now includes ten (overlapping) periods: 1992-1995, 1993-1996, 1994-1997, 1995-1998, 1996-1999, 1997-2000, 1998-2001, 1999-2002, 2000-2003, and 2001-2004 (with the lagged variables starting in 1989-1992 and ending in 1998-2001). Hence, this robustness check uses about 2.5 times more data than the benchmark regressions in sections 4 and 5 .

Using the extra amount of data comes, however, at the cost of mechanically introducing a severe problem of serial correlation (the error term in a period is correlated with the error terms of the previous and following two periods). The good news is that in the presence of serial correlation, our estimation procedure continues to yield unbiased and consistent estimates. The bad news is that these estimates are inefficient and that standard errors are biased (Wooldridge, 2010). We try to minimize this bias by estimating clustered-robust standard errors.

Table 8 presents the results. In comparison to Table 2, the coefficients have the same signs, but are smaller in magnitude. All the coefficients for input trade costs continue to be statistically 
significant at $1 \%$ level and they convey the same story as in section 4: a decline in input trade costs is associated with job destruction for the least productive half of firms and job creation for the other half, with the effect on job creations being larger. On the other hand, the coefficients for final-good trade costs lose their statistical significance for job expansions and the net intensive margin, but gain significance for job contractions. In the comparison of Figures 13d and 13e, we can see that the main difference at the intensive margin is that the case for the higher importance of input trade costs is even stronger.

The conclusions from the death-likelihood regressions from section 5 continue to hold. The coefficients on input trade costs are slightly smaller but continue to be statistically significant at a $1 \%$ level. The coefficients on final-good trade costs are also smaller and continue to be significant (but no longer at a $1 \%$ level). In the end, Figures $14 \mathrm{~d}$ and $14 \mathrm{e}$ present the same story.

\section{Conclusions}

The recent theoretical literature of trade with heterogeneous firms shows that a firm's response to a reduction in trade costs is crucially linked to the firm's relative productivity. With respect to firms' employment responses, the models predict that reductions in input and final-good trade costs cause job destruction at both the intensive and extensive margins for the least productive firms, and possible job expansions for the most productive firms (who are more likely to engage in trade activities). This paper presents evidence from establishment-level data that supports these theoretical predictions.

A key result is that a reduction in input trade costs has larger effects than a reduction in final-good trade costs for establishments' decisions on employment expansions and contractions, as well as for establishments' exit decisions. Not only are the effects of input trade costs larger in magnitude, but establishments seem to respond faster to changes in input trade costs at the intensive-margin of employment. These results suggest that more attention should be directed to understanding the different implications of input and final-good trade costs for firm-level outcomes.

\section{References}

Amiti, M., And D. R. Davis (2011): "Trade, Firms, and Wages: Theory and Evidence," Review of Economic Studies, 79(1), 1-36.

Amiti, M., And J. Konings (2007): "Trade Liberalization, Intermediate Inputs, and Productivity: Evidence from Indonesia," American Economic Review, 97(5), 1611-1638.

Arellano, M., and S. Bond (1991): "Some Tests of Specification for Panel Data: Monte Carlo Evidence and an Application to Employment Equations," Review of Economic Studies, 58(2), $277-97$. 
Arkolakis, C. (2010): "Market Penetration Costs and the New Consumers Margin in International Trade," Journal of Political Economy, 118(6), 1151-1199.

Arkolakis, C., And M.-A. Muendler (2011): "The Extensive Margin of Exporting Products: A Firm-Level Analysis," NBER Working Papers 16641, National Bureau of Economic Research.

Bartelsman, E. J., and M. Doms (2000): "Understanding Productivity: Lessons from Longitudinal Microdata," Journal of Economic Literature, 38(3), 569-594.

Bartelsman, E. J., And W. Gray (1996): "The NBER Manufacturing Productivity Database," NBER Technical Working Papers 0205, National Bureau of Economic Research, Inc.

Bernard, A. B., J. Eaton, J. B. Jensen, and S. Kortum (2003): "Plants and Productivity in International Trade," American Economic Review, 93(4), 1268-1290.

Bernard, A. B., J. B. Jensen, and P. K. Schott (2006a): "Survival of the Best Fit: Exposure to Low-Wage Countries and the (Uneven) Growth of U.S. Manufacturing Plants," Journal of International Economics, 68(1), 219-237.

\section{7-937.}

(2006b): "Trade Costs, Firms and Productivity," Journal of Monetary Economics, 53(5),

Bernard, A. B., S. J. Redding, and P. K. Schott (2007): "Comparative Advantage and Heterogeneous Firms," Review of Economic Studies, 74(1), 31-66.

Biscourp, P., and F. Kramarz (2007): "Employment, Skill Structure and International Trade: Firm-Level Evidence for France," Journal of International Economics, 72(1), 22-51.

Cabral, L. M. B., and J. Mata (2003): "On the Evolution of the Firm Size Distribution: Facts and Theory," American Economic Review, 93(4), 1075-1090.

Davis, S. J., R. J. Faberman, and J. Haltiwanger (2006): "The Flow Approach to Labor Markets: New Data Sources and Micro-Macro Links," Journal of Economic Perspectives, 20(3), $3-26$.

Davis, S. J., J. Haltiwanger, R. S. Jarmin, C. Krizan, J. Miranda, A. Nucci, And K. SAndusky (2009): "Measuring the Dynamics of Young and Small Businesses: Integrating the Employer and Nonemployer Universes," in Producer Dynamics: New Evidence from Micro Data, ed. by T. Dunne, J. B. Jensen, and M. J. Roberts, chap. 9, pp. 329-366. University of Chicago Press, Oxford.

Davis, S. J., J. C. Haltiwanger, and S. Schuh (1996): Job Creation and Destruction. The MIT Press, Cambridge, MA.

Ebenstein, A., A. Harrison, M. McMillan, and S. Phillips (2013): "Estimating the Impact of Trade and Offshoring on American Workers Using the Current Population Surveys," Review of Economics and Statistics, forthcoming.

Estevadeordal, A., C. Freund, and E. Ornelas (2008): "Does Regionalism Affect Trade Liberalization toward Non-Members?," Quarterly Journal of Economics, 123(4), 1531-1575.

Feenstra, R. C., J. Romalis, and P. K. Schott (2002): "U.S. Imports, Exports, and Tariff Data, 1989-2001," NBER Working Papers 9387, National Bureau of Economic Research, Inc.

Goldberg, P. K., A. K. Khandelwal, N. Pavcnik, and P. Topalova (2010): "Imported Intermediate Inputs and Domestic Product Growth: Evidence from India," Quarterly Journal of Economics, 125(4), 1727-1767. 
Goldberg, P. K., And G. Maggi (1999): "Protection for Sale: An Empirical Investigation," American Economic Review, 89(5), 1135-1155.

Goldberg, P. K., and N. Pavcnik (2005): "Trade, Wages, and the Political Economy of Trade Protection: Evidence from the Colombian Trade Reforms," Journal of International Economics, $66(1), 75-105$.

Groizard, J. L., P. Ranjan, and A. Rodriguez-Lopez (2013): "Offshoring, Exporting and Jobs," Working Paper 121312, University of California-Irvine.

Grossman, G. M., and E. Helpman (1994): "Protection for Sale," American Economic Review, $84(4), 833-50$.

Haltiwanger, J., R. S. Jarmin, and J. Miranda (2013): "Who Creates Jobs? Small versus Large versus Young," Review of Economics and Statistics, 95(2), 347-361.

Klein, M. W., S. Schuh, and R. K. Triest (2003): "Job Creation, Job Destruction, and the Real Exchange Rate," Journal of International Economics, 59(2), 239-265.

Levinsohn, J. (1999): "Employment Responses to International Liberalization in Chile," Journal of International Economics, 47(2), 321-344.

Melitz, M. J. (2003): "The Impact of Trade on Intra-Industry Reallocations and Aggregate Industry Productivity," Econometrica, 71(6), 1695-1725.

Melitz, M. J., And S. J. Redding (2013): "Firm Heterogeneity and Aggregate Welfare," NBER Working Papers 18919, National Bureau of Economic Research, Inc.

Moser, C., D. Urban, and B. W. di Mauro (2010): "International Competitiveness, Job Creation and Job Destruction-An Establishment-Level Study of German Job Flows," Journal of International Economics, 80(2), 302 - 317.

Neumark, D., B. Wall, and J. Zhang (2011): "Do Small Businesses Create More Jobs? New Evidence for the United States from the National Establishment Time Series," Review of Economics and Statistics, 93(1), 16-29.

Neumark, D., J. Zhang, and B. Wall (2007): "Employment Dynamics and Business Relocation: New Evidence from the National Establishment Time Series," Research in Labor Economics, $26,39-83$.

Topalova, P., and A. Khandelwal (2011): "Trade Liberalization and Firm Productivity: The Case of India," Review of Economics and Statistics, 93(3), 995-1009.

Trefler, D. (1993): "Trade Liberalization and the Theory of Endogenous Protection: An Econometric Study of U.S. Import Policy," Journal of Political Economy, 101(1), 138-60.

- (2004): "The Long and Short of the Canada-U. S. Free Trade Agreement," American Economic Review, 94(4), 870-895.

Verhoogen, E. A. (2008): "Trade, Quality Upgrading, and Wage Inequality in the Mexican Manufacturing Sector," The Quarterly Journal of Economics, 123(2), 489-530.

Wooldridge, J. M. (2010): Econometric Analysis of Cross Section and Panel Data. MIT press.

YI, K.-M. (2003): "Can Vertical Specialization Explain the Growth of World Trade?," Journal of Political Economy, 111(1), 52-102.

Yu, M. (2014): "Processing Trade, Tariff Reductions, and Firm Productivity: Evidence from Chinese Firms," Economic Journal, forthcoming. 